\title{
Consumer Sentiment During the COVID-19 Pandemic: The Role of Others' Beliefs
}

\author{
Dzung Bui* Lena Dräger† \\ Bernd Hayo; $\quad$ Giang Nghiem ${ }^{\S}$
}

April 9, 2021

\begin{abstract}
This paper investigates the direct and indirect effects of others' beliefs on respondents' own beliefs and consumer sentiment. Conducting consumer surveys with randomized control trials (RCTs) in Thailand and Vietnam during the COVID19 pandemic, we implement two information treatments. Both treatments contain cross-country information about others' beliefs about the appropriateness of the government's or the general public's reaction to the pandemic. The first treatment is asymmetric across our sample countries, as it shows opposite appropriateness ratings of the governments' reaction in Vietnam and Thailand, whereas the second treatment is rather symmetric. We find that the information treatments affect consumer sentiment only in Vietnam, where the sign of the effect suggests that the treatments are viewed as positive news. Moreover, consumer sentiment in Vietnam is strongly affected by both treatments when the information goes against respondents' prior beliefs.
\end{abstract}

Keywords: Consumer sentiment; COVID-19; randomized control trial (RCT); survey experiment; second-order beliefs; belief updating; government trust; macroeconomic expectations; Thailand; Vietnam

JEL classification: E21; E37; E71; D84; D83

*University of Marburg, Universitätsstraße 24, 35037 Marburg, Email: buid@wiwi.uni-marburg.de

${ }^{\dagger}$ Leibniz University of Hannover, Königsworther Platz 1, 30167 Hannover, Email: draeger@gif.unihannover.de

†University of Marburg, Universitätsstraße 24, 35037 Marburg, Email: hayo@wiwi.uni-marburg.de

$\S$ Leibniz University of Hannover, Königsworther Platz 1, 30167 Hannover, Email: nghiem@gif.unihannover.de

We thank seminar participants at the Macroeconomic Policy Institute (IMK) and the Leibniz University Hannover, as well as participants of the $26^{\text {th }}$ IIF Workshop: Economic Forecasting in Times of Covid-19, the $8^{\text {th }}$ International Conference on Applied Research in Economics, and the 11th ifo Conference on Macroeconomics and Survey Data for comments and suggestions. We also thank Carola Binder, Michael Ehrmann, Tobin Hanspal, Baptiste Massenot, Michael Weber and Stephan Thomsen for very valuable comments. 


\section{Introduction}

The COVID-19 virus began spreading around the world in early spring 2020, causing deep crises in many countries. From an economic perspective, the pandemic can be thought of as a triple shock, as it combines elements of a supply, a demand, and an uncertainty shock. These economic shocks likely affect consumer sentiment and, thereby, could dampen current and future spending. At the same time, however, expansive fiscal and monetary policy measures may ease the negative effects of the pandemic on consumer sentiment.

Uncertain times make it difficult for consumers to form expectations about future economic conditions, such as those included in an index of consumer sentiment (Bachmann et al., 2013; Binder, 2020). Thus, individuals may rely on others' beliefs as a guideline to the future economic situation.

In this paper, we use the COVID-19 pandemic to investigate the direct and indirect effect of others' beliefs on respondents' own beliefs and individual consumer sentiment. ${ }^{1}$ To this end, we employ randomized control trials (RCTs) integrated in online consumer surveys conducted in Thailand and Vietnam. ${ }^{2}$ Our information treatments contain crosscountry measures of average beliefs taken from other surveys. We thus study how information about others' beliefs affects respondents' own beliefs and sentiment relative to the control group. Note that this may be related to, but is not necessarily the same as, studying second-order beliefs. Second-order beliefs are beliefs formed about others' beliefs. We, however, study the effect of given information about others' beliefs on respondents' own belief formation.

The first treatment presents average response shares from another survey measuring views about the appropriateness of government response to the COVID-19 crisis (government reaction treatment). Here, we exploit a notable asymmetry among our two sample countries. The cross-country survey by Dölitzsch (2020), which we use for this treatment, finds the lowest average agreement with the government's reaction to the pandemic in Thailand, whereas the highest average agreement is found in Vietnam. We utilize this variation to evaluate whether it matters for our respondents' own beliefs at which end of the distribution tail the beliefs shown in the treatment lie.

\footnotetext{
${ }^{1}$ Individual consumer sentiment is based on the responses to the same questions, which are used to calculate the aggregate consumer sentiment index in the University of Michigan survey. The index accounts for consumers' current and expected financial situation, several macroeconomic expectations, and their readiness to spend on durable goods. The aggregate consumer sentiment index is often employed as a leading indicator for macroeconomic forecasts. A large body of literature highlights the crucial link between consumer sentiment and (future) economic activity such as consumer spending (Carroll et al., 1994; Ludvigson, 2004; Souleles, 2004; Dees and Soares Brinca, 2013; Ahmed and Cassou, 2016), future productivity (Barsky and Sims, 2012; Bachmann and Sims, 2012), and the stock market (Jansen and Nahuis, 2003; Chen, 2011).

${ }^{2}$ The survey took place in May 2020, shortly after easing of the lockdown in both countries. A followup survey was conducted in December 2020, immediately before both countries experienced a second wave of infections.
} 
The second treatment presents evidence on average beliefs about the appropriateness of the general public's response during the COVID-19 crisis in a cross-country survey by Fetzer et al. (2020b) (public reaction treatment). This treatment is symmetric across our sample countries because the average appropriateness ratings in Thailand and Vietnam are relatively similar and lie in the middle of the cross-country distribution, rather than in the tails.

The opposite beliefs in the two countries about the appropriateness of the government's response during the COVID-19 pandemic government reaction can be explained by differences in the economic and political situation in these countries, as well as by different experiences during the pandemic. Economically, GDP per capita in Thailand is roughly twice that in Vietnam and the country ranks higher on the Human Development Index. However, Vietnam experienced high real GDP growth in the years preceding the pandemic. Politically, both nations are governed by unitary entities. The political situation in Vietnam is currently stable, but Thailand has experienced repeated episodes of political unrest since the military coup in 2014. More recent, political instability occurred in Thailand when the election of a new government in 2019 was effectively circumvented by the military. Regarding the COVID-19 pandemic, substantially more cases are reported from Thailand than from Vietnam (both in terms of absolute and per capita numbers) and public disagreement with government policies for handling the crisis is much stronger in Thailand than in Vietnam (Fetzer et al., 2020b; Dölitzsch, 2020). To control for some of these factors, we consider respondents' macroeconomic expectations, beliefs about the government's economic policies before the pandemic, and trust in the government during the pandemic, as well as individual health and financial concerns due to COVID-19.

In the control group not subject to any treatment, we find that consumer sentiment in both countries is correlated with macroeconomic expectations (which are not included in the index), assessment of the government's policies, and personal concerns about COVID19. Consumer sentiment in Thailand and Vietnam is more positive when respondents expect higher GDP growth, think the government did a good job in terms of economic policies before the pandemic, and trust the government in dealing with the economic aspects of the COVID-19 crisis. By contrast, consumers are less optimistic about the economic outlook when they are concerned about the effect of the COVID-19 crisis on their household's financial situation. Hence, even after easing of the lockdown, consumer sentiment is affected by variables related to the COVID-19 crisis. When evaluating the impact of the information treatments on consumer sentiment and on the variables correlated with sentiment, we discover only a few significant effects. These are asymmetric across countries, as it was only our Vietnamese sample that reacted significantly to the treatments in the first survey wave. Given that the government reaction treatment signaled high approval rates in Vietnam and low approval rates in Thailand, the treatment could be viewed as "good" news in Vietnam and as "bad" news in Thailand. Indeed, the Vietnamese respondents stated in the second wave that they regarded the information 
provided in the government reaction treatment, on average, as positive, whereas Thai respondents were more likely to view it as negative. Thus, our results imply that the impact of "good news" is stronger than that of "bad news." This is consistent with Bowman et al. (1999), who show that in the presence of uncertainty and loss aversion, people react more strongly to good news than to bad news. Somewhat surprisingly, we find no direct effect of the information about others' beliefs on respondents' own beliefs. However, significant treatment effects emerge on other expectations or beliefs of the respondents, suggesting that the effect originating from information about others' beliefs is indirect rather than direct. After Vietnamese respondents are treated with information about other Vietnamese consumers' appropriateness ratings of their government and the Vietnamese general public's reaction to the pandemic, they report somewhat more positive consumer sentiment (in the public reaction treatment), as well as higher GDP growth and lower unemployment expectations, and lower concern regarding their health, job security, and household financial situation due to COVID-19. One interpretation of these findings is that both treatments are regarded as good news by Vietnamese consumers.

Conditioning on respondents' assessment of their government's macroeconomic policy before the pandemic (which was elicited before the treatments), we show that significant treatment effects on consumer sentiment emerge when respondents are surprised by the information. For those Vietnamese consumers who think the government did a poor job before the crisis, both the government reaction and the public reaction treatment cause a significant increase in consumer sentiment. The size of this effect is economically meaningful, whereas the magnitude of the other effects is moderate. In the Thai sample, consumers who previously thought the government did a good job are found to be more pessimistic after receiving the government reaction or the public reaction treatment, although these effects are not statistically significant. This suggests that information about other people's beliefs affects consumer sentiment more strongly when the information contradicts the individual's prior belief.

Our paper contributes to the growing literature that combines consumer surveys with RCTs to study economic aspects of the COVID-19 pandemic. To date, however, most studies focus on the United States and were conducted at the beginning of the pandemic. Fetzer et al. (2020) conducted two survey experiments at the start of the pandemic in the United States, that is, in early-mid March 2020. They show that providing information about true contagiousness or mortality significantly lessens concerns over the individual or the aggregate economic situation. While Fetzer et al. (2020) measure economic sentiment using questions on personal economic concerns related to COVID-19, we calculate an individual index of consumer sentiment based on financial and macroeconomic expectations as well as the readiness to spend on durable goods. Binder (2020) surveyed U.S. consumers on March 5 and 6, 2020, just before the pandemic really hit the United States. She finds that consumers concerned about COVID-19 expect higher unemployment and higher inflation and, thus, are more pessimistic about the economic outlook. When treated with 
information about the Fed's interest rate cut on March 3, 2020, consumers become more optimistic about future unemployment and inflation. Similarly, Coibion et al. (2020a) conducted a survey of Nielsen Homescan panelists in April 2020 and randomly provided several information treatments about the severity of the pandemic and monetary, fiscal, and health policies in the United States. They find no notable effects of information about policy responses on macroeconomic expectations or planned spending. Hanspal et al. (2020) surveyed U.S. consumers in April 2020 and included RCT information treatments referring to several historical stock market crashes. The authors find that those who received information about a more severe stock market crash in the past are more pessimistic about current stock market development. Most recently, Coibion et al. (2020c) conducted a survey from October 19-21, 2020 in the United States to study the effect of the expected presidential election outcome on economic expectations. The authors find that providing public polling information significantly changes the opinions of only those respondents who are political independents and/or have no strong initial beliefs about the outcome.

We utilize the results from two global surveys as our two information treatments. From March 23 to March 27, 2020, Dölitzsch (2020) at the Dalia Research Company conducted a global survey to assess citizen rankings of their government's response to the COVID-19 crisis. The survey covered 45 countries across all continents and had more than 32,000 respondents. Dölitzsch (2020) reports that among the 45 surveyed countries, Thailand has the highest share of respondents who believe their government responds too little to the pandemic, while Vietnam has the highest share of respondents who believe their government responds appropriately. We take this result as our first information treatment (government reaction). The study by Fetzer et al. (2020a) evaluates the effect of the government's reaction to COVID-19 on mental well-being in a large-scale survey covering 58 countries and over 100,000 respondents between March 20 and April 7, 2020. The authors find that the perception of insufficient public and government response is associated with lower mental well-being, leading to pessimism or even psychological illnesses. We use the Fetzer et al. (2020b) survey results on the global assessment of the public's reaction to COVID-19 as our second information treatment (public reaction).

Our paper also adds to a large body of work on good news-bad news effects. Bowman et al. (1999) develop theoretical models based on Kahneman and Tversky's prospect theory and conclude that due to loss aversion and income uncertainty, individual consumption responds more strongly to good news than to bad news. Using controlled laboratory experiments, Eil and Rao (2011) and Kuhnen (2014) report empirical evidence that people put more weight on good news compared to bad news, whereas Coutts (2019) and Barron (2021) find no such asymmetric effects.

More generally, our paper is also related to the literature studying the impact of the COVID-19 pandemic on consumption, a body of work that includes, among others, Andersen et al. (2020), Baker et al. (2020), Carvalho et al. (2020), Christelis et al. (2020), 
and Chronopoulos et al. (2020). To the best of our knowledge, the only other study to date on the impact of COVID-19 on consumers in our sample countries is by Dang and Giang (2020). To study the correlation of employment status with household financial situation and economic expectations in Vietnam, the authors conducted an online survey from April 26 to May 9, 2020. They find that having a job is positively correlated with a better financial situation, fewer job concerns, and more optimism with respect to future economic development.

Overall, our study extends the literature by employing a survey-based RCT framework to study the effect of others' beliefs on consumer sentiment during COVID-19 in Thailand and Vietnam. As our main contribution, we use cross-country variation in others' average beliefs about the appropriateness of government response during the pandemic to test whether this information affects respondents' own beliefs, expectations, or concerns and, ultimately, individual consumer sentiment. Our RCT framework allows us to test for an effect of average beliefs of others and to distinguish between positive and negative news. The rest of the paper is organized as follows. In the next section, we describe our survey and the treatments. Section 3 contains the results of our analysis. Section 4 concludes.

\section{Data Description}

In early May 2020, when there was an easing of the lockdown in both countries, we conducted two online surveys of consumers in Vietnam and Thailand. This is a novel dataset because it collects consumer opinions on trust in the government, macroeconomic expectations, and personal concerns, as well as consumer sentiment during the COVID-19 pandemic in two emerging economies. As a unique feature of our dataset, we randomly selected respondents into two treatment groups and a control group. The treatments test how information about others' average beliefs on the appropriateness of the government's or the general public's response to the crisis affects respondents' own beliefs, macroeconomic expectations, and consumer sentiment. A follow-up survey of a subsample of respondents from the first wave was conducted in December 2020.

Thailand and Vietnam are similar along some dimensions, but differ in others. On the one hand, both are emerging countries from the same geographic region. Politically, they are both ruled by unitary entities: the Kingdom of Thailand is currently governed by the military and the Socialist Republic of Vietnam by the Communist Party. They also have fairly comparable population sizes (Thailand: 67 million, Vietnam: 95 million). On the other hand, Thailand has roughly twice the GDP per capita as Vietnam (about $\$ 20,000$ and $\$ 8,000$, respectively (U.S. dollar in PPP in 2019)) and ranks higher on the Human Development Index (ranks of 77 and 118, respectively). The recent real GDP growth and inflation development in both countries are shown in Figure A1 in the Appendix.

As Figure 1 shows, substantially more COVID-19 cases are reported from Thailand than from Vietnam (both in terms of absolute and per capita numbers). Both countries 
experienced a second wave of infections shortly after our second survey in December 2020. Following the lockdown in the spring of 2020, widespread anti-government protests erupted in Thailand, whereas Vietnam remained calm. Moreover, perceptions of the government reaction to the crisis differ between the two countries. As shown by Fetzer et al. (2020b), in Vietnam, public agreement with policy measures is much higher than in Thailand and trust in the government is also substantially higher.

The survey in Vietnam covers 3,300 respondents and was conducted May 4-9, 2020; the survey in Thailand took place May 4-10, 2020 and includes 2,200 respondents. The May 2020 survey contained two additional treatments that we do not analyze in this study. The relevant samples for this paper are 1,980 respondents from Vietnam and 1,320 respondents from Thailand. In addition, we conducted a follow-up survey December 18-27, 2020 and re-interviewed 1,016 Vietnamese and 1,189 Thai respondents from the first wave. In this follow-up survey, we randomly sorted respondents who received one of the two other treatments (i.e., one of the two treatments that are not analyzing in the present paper) in the first wave into treatments groups for the government reaction and the public reaction treatments. This was done to evaluate whether the timing of the treatment during the specific phase of the pandemic matters and, more generally, whether the information treatments are externally reliable and generate similar effects more than half a year later. Members of the initial control group who did not receive a treatment in May 2020 were also re-interviewed in the second survey wave.

The data were collected by GMO-Z.com RUNSYSTEM, which is one of the largest private market research and public opinion survey companies in South-East Asia. The company has a large number of registered participants who are familiar with online surveys. Participants can gain "reward points," which are redeemable as gifts, by finishing the survey. Our datasets overweight the young, highly educated, and urban respondents in both countries. To improve the representativeness of our data, we construct and apply population weights based on the official age distribution, the main factor distorting our sample. We also make sure that our results are generally robust when applying education and share of the urban population weights. All estimations control for these factors and several additional demographic characteristics, including income, employment status, gender, and marital status. 
Figure 1: COVID-19 Pandemic Development in Thailand and Vietnam

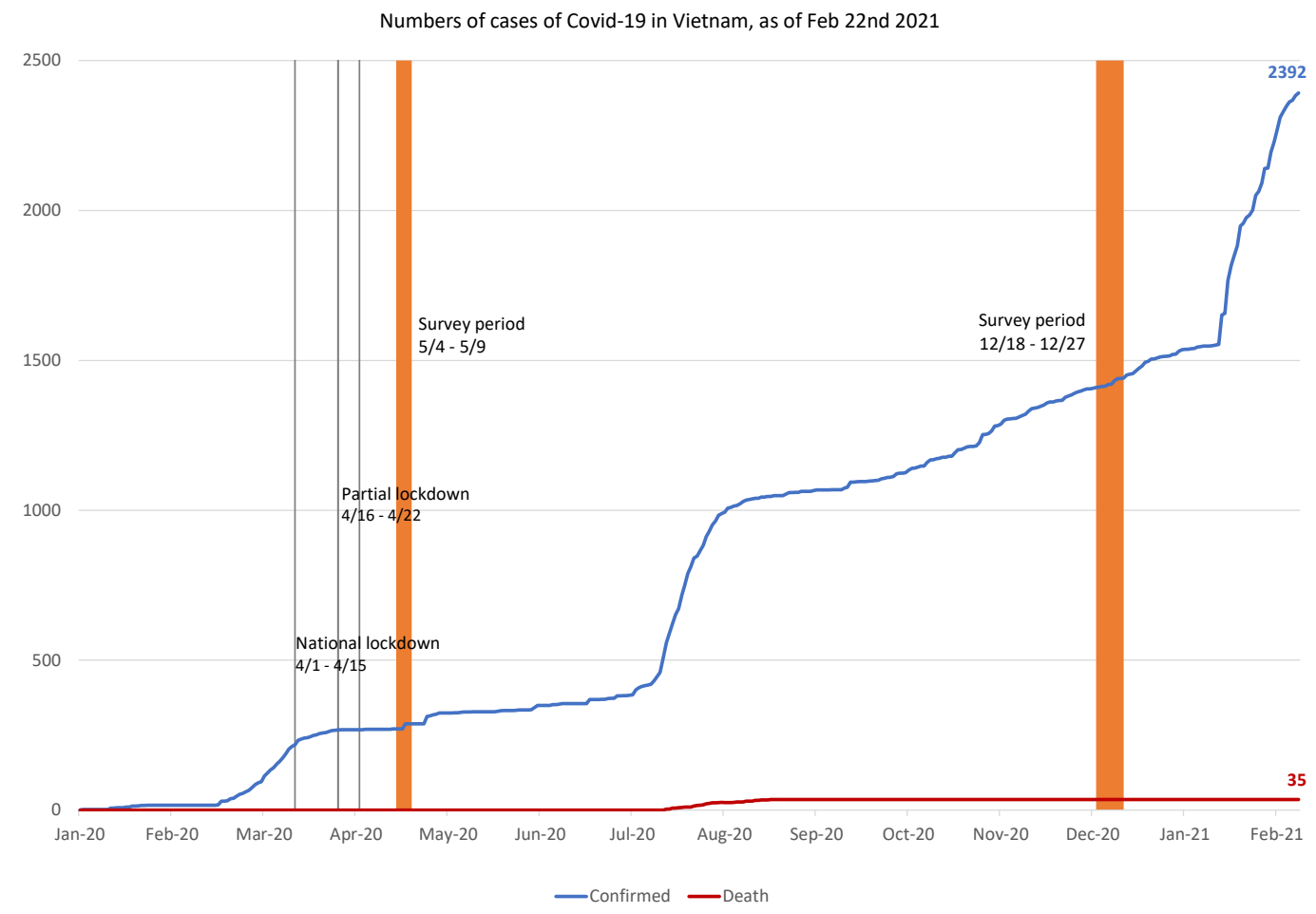

(a) Vietnam

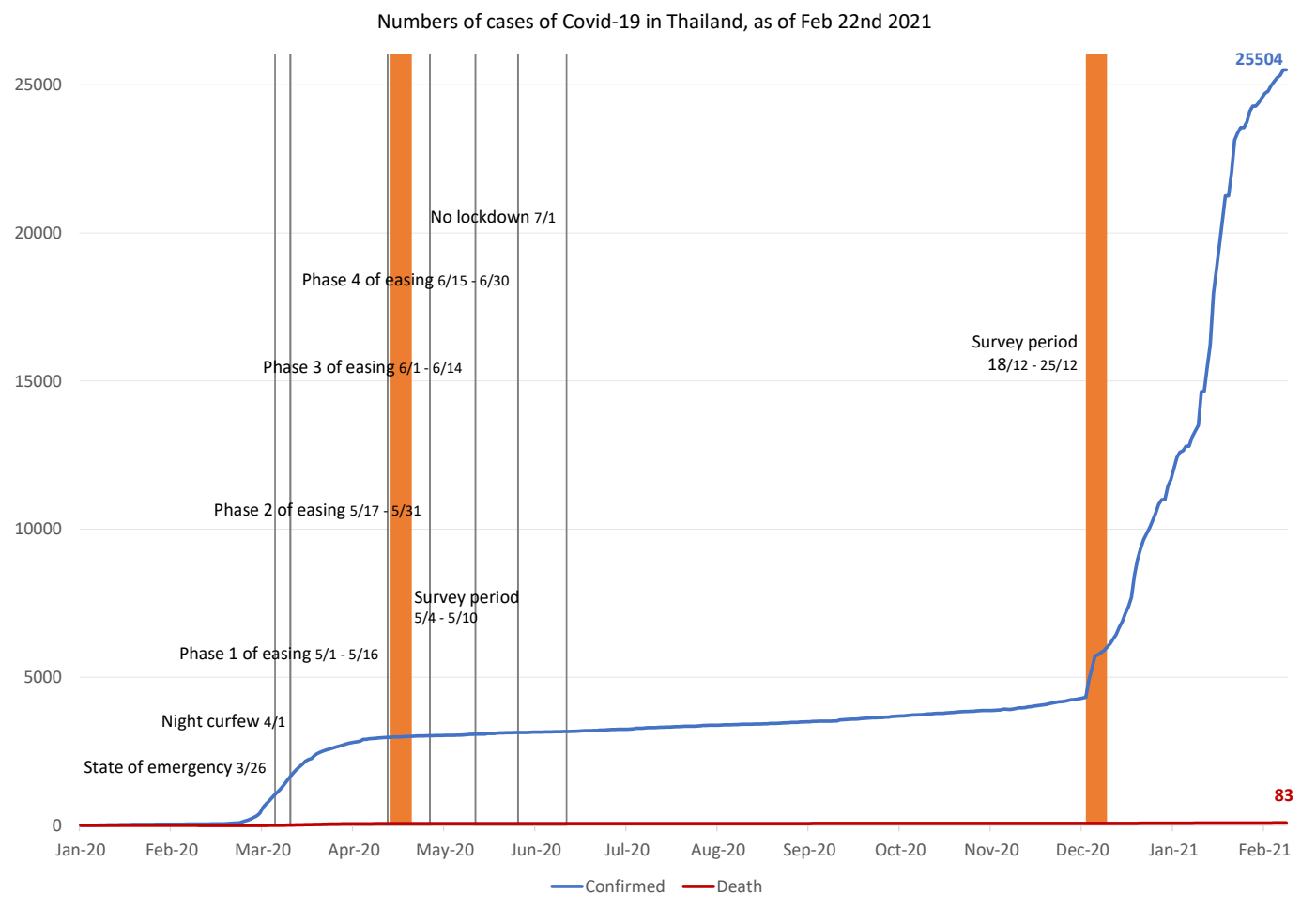

(b) Thailand

Source: John Hopkins University, Worldometers. 


\subsection{Information Treatments}

The May 2020 questionnaire starts with a set of standardized questions designed to elicit consumers' sociodemographic characteristics and their assessment of the government's macroeconomic policies before COVID-19 (govt_ass_normal_times). ${ }^{3}$ We then randomly divide our samples for each country and apply four different information treatments; there is also a control group that does not receive any information. In this paper, we study the following information treatments, which are focused on the effect of presenting information about the beliefs of others.

\section{Treatment 1: Government reaction}

- Thailand survey:

COVID-19: Many Thai believe that their government responds too little.

A global survey pointed out that about 8 out of 10 Thai surveyed said that the government has not implemented sufficient measures to control the spread of the COVID-19 pandemic. Among 45 countries, Thailand has the highest share of respondents who believe that their government responds too little.

- Vietnam survey:

COVID-19: Many Vietnamese people believe that their government responds appropriately.

A global survey pointed out that about 6 out of 10 Vietnamese surveyed said that the government has implemented appropriate measures to control the spread of the COVID-19 pandemic. Among 45 countries, Vietnam has the highest share of respondents who believe that their government responds appropriately.

\footnotetext{
${ }^{3}$ The question on govt_ass_normal_times is taken from the Michigan Survey of Consumers.
} 
Figure 2: Assessment of the Government's Reaction to the Covid-19 Pandemic

\begin{abstract}
Judgment by country about the
response of their governments to the COVID-19 pandemic.
\end{abstract}

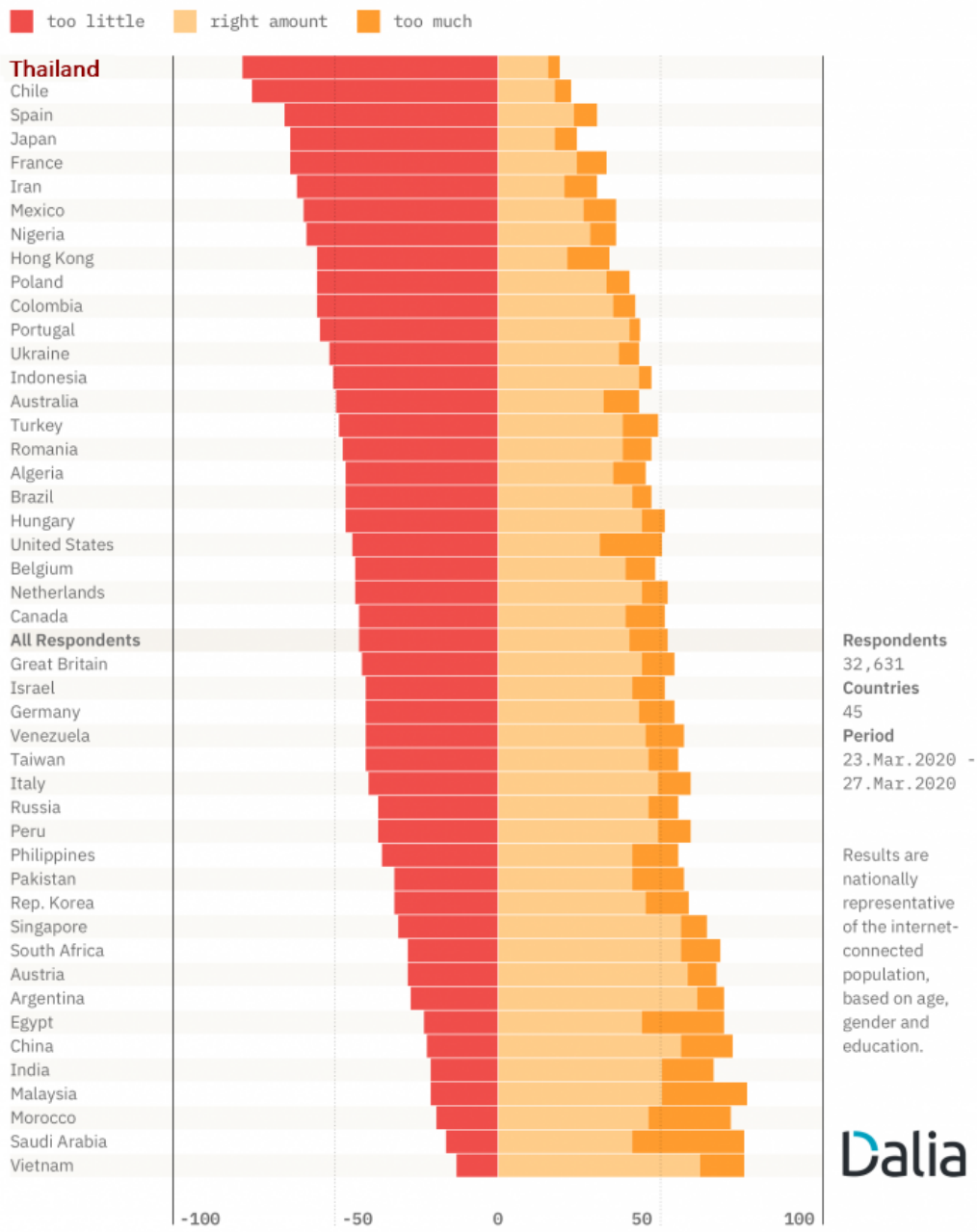

Source: Dalia Research Company, Dölitzsch (2020). 


\section{Treatment 2: Public reaction}

- Thailand survey:

About half of Thai said that the public's reaction in their country is insufficient.

A recent global population survey asked how people assess the public's reaction in their country to the COVID-19 crisis. About 5 out of 10 Thai said that the reaction of their fellow citizens is insufficient. Worldwide, only about 1 out of 10 Chinese, but about 10 out of 10 Indians, gave the same answer.

- Vietnam survey:

COVID-19 survey: About 6 out of 10 Vietnamese said that the public's reaction in their country is insufficient.

A recent global population survey asked how people assess the public's reaction in their country to the COVID-19 crisis. About 6 out of 10 Vietnamese said that the reaction of their fellow citizens is insufficient. Worldwide, only about 1 out of 10 Chinese, but about 10 out of 10 Indians, gave the same answer.

Figure 3: Assessment of the Public's Reaction to the Covid-19 Pandemic
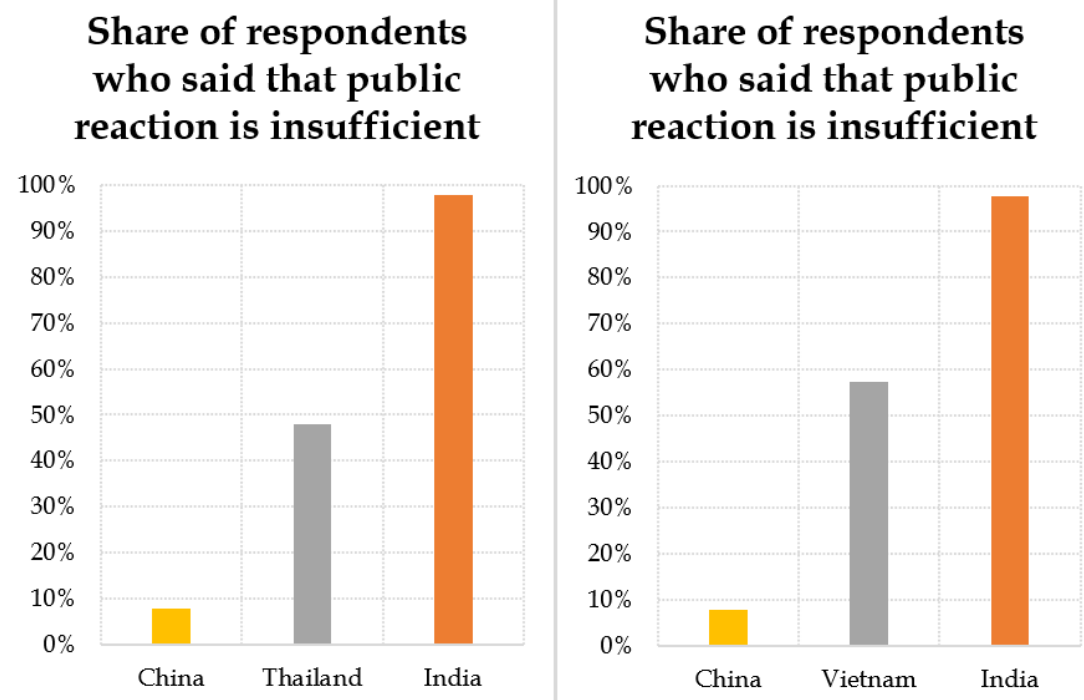

Source: Fetzer et al. (2020b). 
Treatments 1 and 2 summarize the results of the global surveys by Dölitzsch (2020) and Fetzer et al. (2020b) about respondents' assessment of the appropriateness of their government's reaction to the COVID-19 pandemic (Treatment 1 - government reaction) and of the appropriateness of the general public's reaction (Treatment 2 - public reaction). Thus, both treatments test for an effect of information about other consumers' beliefs on our respondents' beliefs and sentiment. Although the treatments as such are symmetric across countries, Treatment 1 places the countries at opposite extremes, as Thailand is the country with the highest disagreement with government policies during the pandemic, whereas Vietnam has the highest approval rate. In contrast, Treatment 2 places the two countries' similar appropriateness ratings between those of the two largest Asian economies, China and India. Hence, this treatment is not asymmetric between the two countries.

In our follow-up survey in December 2020, we randomly assigned Treatments 1 and 2 to members of two treatment groups in May who had not previously received these treatments. After the treatment information was shown, we asked them whether it was new information. Figure A3a,b in the Appendix shows that both treatments were viewed as new information by about $80 \%$ of respondents, except for the government reaction (Treatment 1), which only about $64 \%$ of Vietnamese respondents regarded as new information in December 2020.

We further use the follow-up survey to evaluate whether respondents regard the information in Treatments 1 and 2 as good, neutral, or bad, where values of 1,2 , and 3 are assigned to these answers, respectively. As shown in Figure A3c, on average, Vietnamese respondents view the government reaction treatment as good news (average response value of about 1.5), whereas Thai respondents regard it as negative news (average response value of about 2.3). By contrast, the public reaction treatment is evaluated more similarly in both countries. Vietnamese respondents regard this treatment as neutral on average, whereas Thai respondents perceive it as slightly negative (Figure A3d).

Finally, as we use academic and scientific research results for our information treatments, in the follow-up survey, we ask all respondents how much they trust scientific research/scientists in general (scale from 1 - strongly distrust to 5 - strongly trust). Figure A2 in the Appendix shows that respondents in both countries have a relatively strong trust in science, with average ratings of 4.1 and 3.8 in Vietnam and Thailand, respectively. It is thus likely that our respondents regard the treatments as reliable information.

\subsection{Key Variables of Interest}

After providing information treatments, we collect a set of questions about people's trust in and assessment of the government's responses to COVID-19, their macroeconomic expectations, personal concerns related to COVID-19, and consumer sentiment. The exact wording of these questions can be found in Appendix A.3. We first ask about the perceived 
appropriateness of the government's reaction to COVID-19 and create a dummy variable, govt_covid_appropriate, which takes the value of unity when the respondent thinks the reaction is "appropriate" and zero otherwise. We then ask about a qualitative level of trust in the government in overcoming the COVID-19 pandemic, govt_trust_covid_health, and in mitigating the negative effects on the economy, govt_trust_covid_econ. The questions on trust are taken from Fetzer et al. (2020b). Next, we collect qualitative macroeconomic expectations for the next 12 months, including expected inflation $\left(\pi^{e}\right)$, unemployment $\left(u^{e}\right)$, and GDP growth $\left(y^{e}\right)$. Personal concerns due to COVID-19 include respondents' health (concern_health), their job security (concern_job), their financial situation (concern_finance), and the economy in general (concern_econ). The questions on personal concerns are taken from Binder (2020) and Fetzer et al. (2020). We calculate the consumer sentiment index for each respondent as a simple average of the five questions: (1) financial situation in the past 12 months, (2) expected financial situation in the next 12 months, (3) expected national business conditions in the next 12 months, (4) national economic situation in the next five years, (5) current readiness to spend on durable goods. ${ }^{4}$

For the baseline analysis, we exclude respondents who do not know the answer or who do not have opinions about the questions used in our main analysis. This results in the first survey wave in May 2020 having 1,478 Vietnamese and 720 Thai respondents. In Appendix A.2, we re-estimate all regressions with an extended sample, assuming that respondents can be categorized as having a neutral position (i.e., expecting "no change" or viewing policies as "neither appropriate or inappropriate" or being "not concerned at all") when they do not know the answer or report that they have no opinion. We thus recode missing answers as neutral for the variables of the index of consumer sentiment as well as the regressors in Table 2, that is, further macroeconomic expectations, trust in the government, and personal concerns related to COVID-19. ${ }^{5}$ For these robustness checks, we have 1,980 observations in Vietnam and 1,320 observations in Thailand.

Table 1 presents the summary statistics of all our variables of interest for the control group, which does not receive any information treatments. As a neutral consumer sentiment has a value of 3 (by construction, the minimum of the index is 1 , the maximum is 5), we see that Vietnamese consumers in the control group are, on average, somewhat optimistic, while the opposite is true for the Thai sample. Regarding their macroeconomic expectations, consumers in both countries have similar opinions about inflation expectations, but the Thai consumers are more pessimistic about future unemployment and economic growth. Vietnamese consumers have strong agreement with and remark-

\footnotetext{
${ }^{4}$ The consumer sentiment index of the University of Michigan is calculated only at the aggregate level by first computing the relative scores (the share of respondents giving favorable replies minus the share giving unfavorable replies) for each of the five questions, then taking the simple average of these five scores.

${ }^{5}$ A similar approach is taken by the University of Michigan Surveys of Consumers and Statistics Netherlands in their respective calculations of aggregate indices of consumer sentiment or consumer confidence. Since these indices are calculated by evaluating the difference in shares of positive and negative answers, all other answers (including missing values) are implicitly treated as neutral.
} 


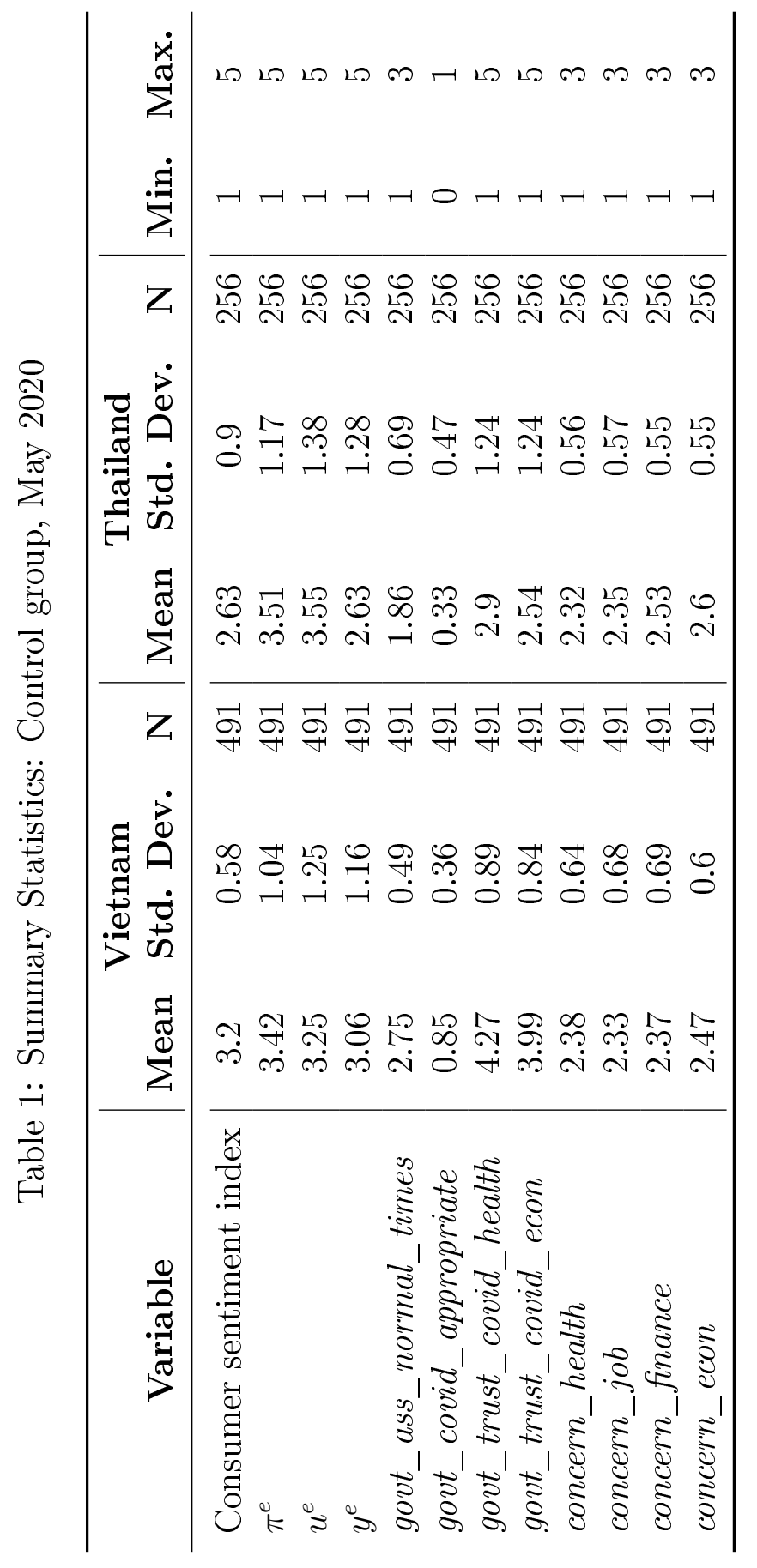


able trust in government policies during normal times, and also in those dealing with the health and economic aspects of the COVID-19 pandemic, whereas Thai interviewees express the opposite opinion. These results are consistent with Dölitzsch (2020) and Fetzer et al. (2020b). The final part of Table 1 shows the statistics for personal concerns due to COVID-19. Interestingly, despite having different assessments of and trust in the government in dealing with the pandemic, health concerns due to the pandemic are quite similar in both countries. However, the Thai consumers report somewhat higher average concerns about their financial situation and the economy in general.

\section{Results}

\subsection{Consumer Sentiment, Macro Expectations, Trust in the Gov- ernment, and Concerns due to COVID-19}

We commence our analysis by looking at whether macroeconomic expectations, assessment of and trust in government policies, and concerns related to the pandemic are associated with consumer sentiment among the respondents of the control group. We thus first evaluate unconditional correlations before proceeding to evaluate causal effects from our information treatments. In their survey of U.S. consumers during the early stages of the COVID-19 pandemic, Fetzer et al. (2020) show that overestimation of the contagiousness and mortality of the virus is negatively related to concerns over the negative effects of the pandemic, overall leading to higher economic anxiety. We study consumer sentiment in Vietnam and Thailand shortly after the end of the lockdown, thus exploring whether adverse effects on sentiment persist beyond the immediate lockdown phase.

Note that consumers' macroeconomic expectations, which are not part of the consumer sentiment index, may be linked to sentiment via several channels. On the one hand, following an Euler equation logic, there could be a positive correlation of inflation expectations with consumer sentiment, at least when interpreting sentiment as a proxy for actual consumption spending (Crump et al., 2015; D'Acunto et al., 2016; Vellekoop and Wiederholt, 2019; Dräger and Nghiem, 2020; Duca-Radu et al., 2021). On the other hand, if consumers view higher expected inflation as a signal for bad future economic outcomes, a negative correlation would also be possible (Bachmann et al., 2015; Coibion et al., 2019). Since expected unemployment and expected GDP growth are proxies for the future macroeconomic situation, we would expect a negative correlation of consumer sentiment with expected unemployment and a positive correlation with expected GDP growth.

Table 2 sets out the results for Vietnam and Thailand, controlling for demographic effects. Columns (1) and (2) show the results using the first survey wave in May 2020, while Columns (3) and (4) control for individual fixed effects of respondents in the control group, who were re-interviewed in the second survey wave in December 2020 (again, in 
the control group). In both countries, higher expected GDP growth is related to more optimistic sentiment. The correlation is notable, but the estimated effect is not large, as a 1 standard deviation (s.d.) increase in expected GDP growth $\left(y^{e}\right)$ in both countries is associated with an increase in consumer sentiment of about 0.3 s.d. ${ }^{6}$ Moreover, in the Vietnamese sample, we find that higher expected inflation is significantly associated with more optimistic consumer sentiment, whereas higher expected unemployment is associated with more pessimistic sentiment. Thus, the link between inflation expectations and sentiment is in line with an Euler equation logic. Neither effect is statistically significant in the Thai sample. Once we control for individual fixed effects, the positive correlation between individual consumer sentiment and respondents' GDP growth expectations in Thailand and Vietnam, as well as the positive correlation with inflation expectations in the Vietnamese sample, remains significant.

Regarding the assessment of and trust in government policies in the control group, the May 2020 results in Columns (1) and (2) of Table 2 show that consumer sentiment significantly co-moves with a more positive assessment of the government's general economic policy during normal times in both countries. A 1 s.d. higher assessment of the government is associated with a $0.2 \mathrm{~s} . d$. higher consumer sentiment. However, in both countries, the overall assessment of the government's policies during the pandemic or the level of trust in the government's ability to deal with the health aspects of the pandemic do not significantly relate to consumer sentiment. We find that consumers' trust in the ability of the government to fight the negative economic externalities of the pandemic is positively correlated with consumer sentiment in Vietnam, but not in Thailand. Controlling for individual fixed effects in Columns (3) and (4), the positive correlation of sentiment with assessment of the government during normal times disappears, but a significantly positive correlation with trusting the government to fight the negative economic effects of the pandemic emerges for Thailand.

Finally, we find that in both countries greater concerns regarding a household's financial situation due to COVID-19 are negatively correlated with consumer sentiment. In that sense, our results corroborate the findings by Fetzer et al. (2020) for the consumer sentiment index. However, the magnitude of this effect is small: an increase of 1 s.d. results in a 0.2 s.d. less positive consumer sentiment. Note that if we estimate the regressions with concern_job and concern_finance separately, we discover that concerns about job security are significantly associated with less positive sentiment in both countries. In addition, once we capture individual-specific effects in the panel fixed effects estimations, personal concerns do not correlate with individual sentiment.

Overall, macroeconomic expectations and, to some extent, concerns raised by the pandemic and trust in the government's ability to deal with it are significantly related

\footnotetext{
${ }^{6}$ To measure this relation, we use the respective cross-sectional standard deviations for each country given in Table 1.
} 
Table 2: Consumer Sentiment: Control Group

\begin{tabular}{|c|c|c|c|c|}
\hline & $\begin{array}{c}\text { OLS M } \\
(1) \\
\text { VN }\end{array}$ & $\begin{array}{l}020 \text { Sample } \\
(2) \\
\text { TL }\end{array}$ & $\begin{array}{l}\text { Panel } \\
(3) \\
\text { VN }\end{array}$ & $\begin{array}{l}\text { Effects } \\
(4) \\
\text { TL }\end{array}$ \\
\hline$\pi^{e}$ & $\begin{array}{c}0.07^{* * *} \\
(0.02)\end{array}$ & $\begin{array}{c}0.05 \\
(0.05)\end{array}$ & $\begin{array}{l}0.1^{* * *} \\
(0.03)\end{array}$ & $\begin{array}{c}0.07 \\
(0.07)\end{array}$ \\
\hline$u^{e}$ & $\begin{array}{c}-0.05^{* *} \\
(0.02)\end{array}$ & $\begin{array}{l}-0.05 \\
(0.04)\end{array}$ & $\begin{array}{l}0.010 \\
(0.05)\end{array}$ & $\begin{array}{c}-0.1 \\
(0.07)\end{array}$ \\
\hline$y^{e}$ & $\begin{array}{l}0.2^{* * *} \\
(0.03)\end{array}$ & $\begin{array}{l}0.3^{* * *} \\
(0.05)\end{array}$ & $\begin{array}{l}0.2^{* * *} \\
(0.04)\end{array}$ & $\begin{array}{l}0.3^{* * *} \\
(0.07)\end{array}$ \\
\hline govt_assess_normal_times & $\begin{array}{c}0.1^{* *} \\
(0.06)\end{array}$ & $\begin{array}{l}0.3^{* * *} \\
(0.10)\end{array}$ & $\begin{array}{c}0.03 \\
(0.11)\end{array}$ & $\begin{array}{c}0.3 \\
(0.19)\end{array}$ \\
\hline govt_covid_appropriate & $\begin{array}{l}-0.06 \\
(0.08)\end{array}$ & $\begin{array}{c}0.02 \\
(0.13)\end{array}$ & $\begin{array}{c}0.05 \\
(0.10)\end{array}$ & $\begin{array}{l}-0.05 \\
(0.22)\end{array}$ \\
\hline govt_trust_covid_health & $\begin{array}{c}0.02 \\
(0.03)\end{array}$ & $\begin{array}{c}-0.006 \\
(0.07)\end{array}$ & $\begin{array}{l}-0.01 \\
(0.05)\end{array}$ & $\begin{array}{c}0.02 \\
(0.08)\end{array}$ \\
\hline govt_trust_covid_econ & $\begin{array}{c}0.07^{* *} \\
(0.03)\end{array}$ & $\begin{array}{r}-0.008 \\
(0.06)\end{array}$ & $\begin{array}{l}-0.005 \\
(0.05)\end{array}$ & $\begin{array}{c}0.2^{* *} \\
(0.10)\end{array}$ \\
\hline concern_health & $\begin{array}{l}-0.02 \\
(0.05)\end{array}$ & $\begin{array}{c}-0.0004 \\
(0.10)\end{array}$ & $\begin{array}{l}-0.05 \\
(0.08)\end{array}$ & $\begin{array}{c}0.02 \\
(0.19)\end{array}$ \\
\hline concern_job & $\begin{array}{l}-0.04 \\
(0.05)\end{array}$ & $\begin{array}{l}-0.03 \\
(0.11)\end{array}$ & $\begin{array}{c}0.05 \\
(0.07)\end{array}$ & $\begin{array}{c}-0.4 \\
(0.24)\end{array}$ \\
\hline concern_finance concern_finance & $\begin{array}{c}-0.1^{* * *} \\
(0.05)\end{array}$ & $\begin{array}{c}-0.3^{* * *} \\
(0.11)\end{array}$ & $\begin{array}{l}-0.05 \\
(0.08)\end{array}$ & $\begin{array}{l}-0.02 \\
(0.22)\end{array}$ \\
\hline concern_econ & $\begin{array}{c}0.04 \\
(0.06)\end{array}$ & $\begin{array}{c}-0.1 \\
(0.12)\end{array}$ & $\begin{array}{c}0.08 \\
(0.08)\end{array}$ & $\begin{array}{c}-0.2 \\
(0.21)\end{array}$ \\
\hline $\begin{array}{l}\text { Demographic controls } \\
\mathrm{R}^{2} \\
\mathrm{~N} \text { observations }\end{array}$ & $\begin{array}{c}\text { Yes } \\
0.462 \\
491\end{array}$ & $\begin{array}{c}\text { Yes } \\
0.432 \\
256\end{array}$ & $\begin{array}{c}\text { Yes } \\
0.391 \\
351\end{array}$ & $\begin{array}{c}\text { Yes } \\
0.573 \\
218\end{array}$ \\
\hline
\end{tabular}

Note: Demographic controls include the log of household income per capita, employment status, urban/rural area, age, age squared, gender and marital status. We report coefficients from OLS estimations with population weights. Standard errors are in parentheses. $p<0.10,{ }^{* *} p<0.05,{ }^{* * *} p<0.01$

to consumer sentiment even after moving out of the immediate lockdown phase. ${ }^{7}$ We discover these effects in both Vietnam and Thailand, two emerging markets with marked differences in terms of agreement with and trust in the government. Our estimates suggest that the pandemic has relatively long-lasting negative effects on consumption spending,

\footnotetext{
${ }^{7}$ As shown in Table A1 in the Appendix, our results mostly remain unchanged when we use the full sample, that is, when assuming respondents are neutral when they answer "don't know" or "do not form opinions" to the survey questions.
} 
particularly when the resulting recession is anticipated to be bad and there is little trust in the government's ability to deal with the pandemic and the recession.

\subsection{Causal Effects of Information Treatments}

To this point, we have considered multivariate correlations in the control group. In this section, we evaluate the causal effects of the information treatments discussed in Section 2. Treatments 1 and 2 summarize the results of the global surveys by Dölitzsch (2020) and Fetzer et al. (2020b) about respondents' assessment of the appropriateness of the government's reaction to the COVID-19 pandemic (Treatment 1 - government reaction) and of the appropriateness of the general public's reaction (Treatment 2 - public reaction). As discussed in Section 2.1, in Treatments 1 and 2, we test for an effect of other consumers' beliefs. In addition, Treatments 1 and 2 test whether it makes a difference how average views in the respondents' own country compare to those in other countries.

Table 3 analyzes whether the information about the cross-country distribution of others' beliefs affects consumers' own beliefs. It sets out estimated treatment effects of the government reaction and the public reaction treatments on respondents' own assessment of the appropriateness of the government's reaction as well as on trust in the government to deal with the health and the economic aspects of the pandemic. The results show that there are no significant treatment effects on either of these variables. This implies that the information treatments have no direct effects on respondents' own beliefs about the appropriateness of the government's reaction or on their trust in the government.

After ruling out any direct effects of second-order beliefs on respondents' own belief formation, we test whether the treatment changes consumer sentiment or the drivers of sentiment discussed in the previous section. The rationale is as follows. Even if showing respondents information about the cross-country distribution of average response appropriateness ratings does not affect their own views about the government response, it could still serve as a signal about the general situation in the country. A high approval rating compared to that in other countries could be regarded as a positive signal about the home country's ability to fight the pandemic and vice versa. As we discussed in Section 2, on average, the government reaction treatment was perceived as good news for Vietnamese respondents and as bad news for Thai respondents, whereas the public reaction treatment was considered to be roughly neutral information for both countries.

Table 4 shows that most information treatment effects are insignificant for the consumer sentiment index. The only exception is a significantly positive effect at the $10 \%$ level of the public reaction treatment on consumer sentiment in Vietnam. Compared to the control group, this implies that respondents receiving the public reaction treatment increase their consumer sentiment by about 0.15 standard deviations, a rather small upswing. However, this suggests that the information is perceived as a positive signal for consumption spending, even though the news itself was regarded as neutral, as demon- 


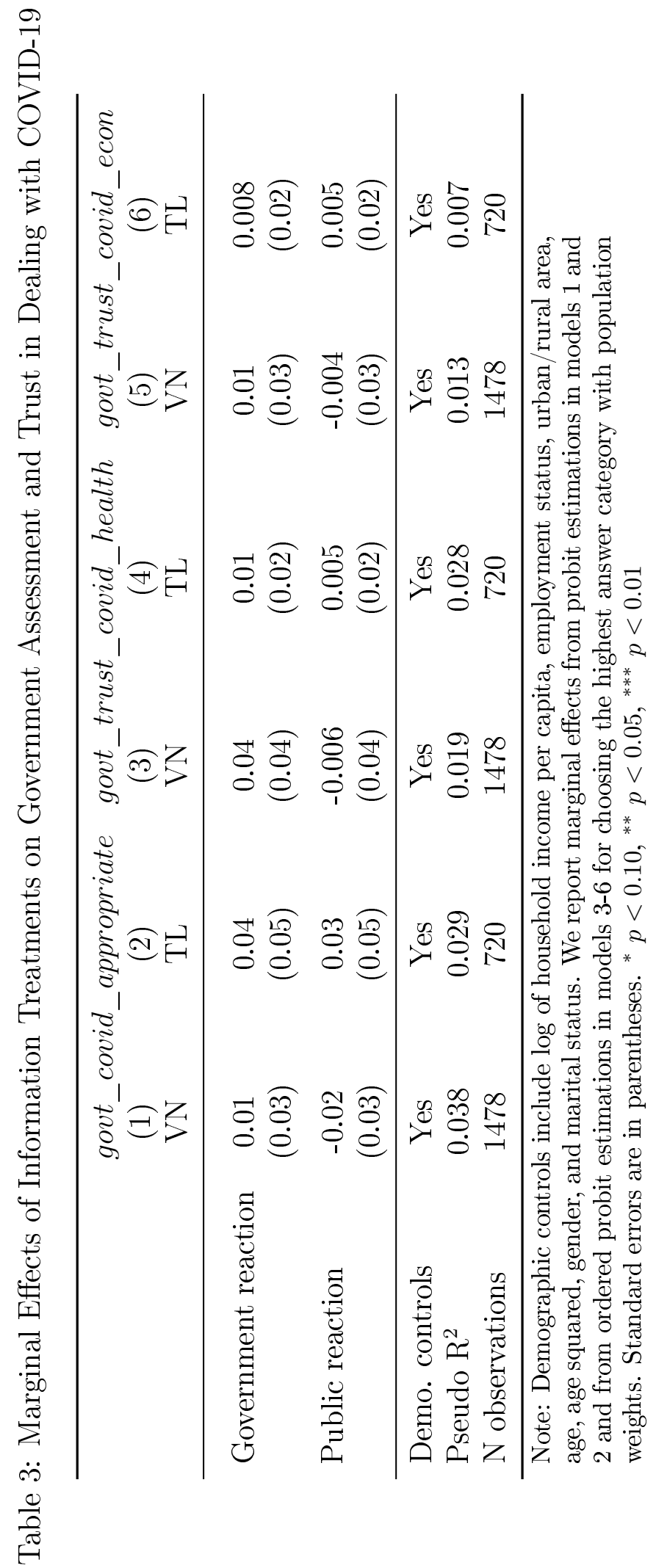


strated by the answers to a corresponding question in our follow-up survey in December 2020. Overall, our finding of few significant information treatment effects is consistent with Coibion et al. (2020a), who find very small effects of information about various policy measures on respondents' beliefs or spending plans in the United States during the start of the COVID-19 lockdown.

Table 4: Marginal Effects of Information Treatments on Consumer Sentiment

\begin{tabular}{lcc}
\hline & $(1)$ & $(2)$ \\
& VN & TL \\
\hline Government reaction & 0.06 & -0.10 \\
& $(0.05)$ & $(0.10)$ \\
Public reaction & $0.09^{*}$ & -0.1 \\
& $(0.05)$ & $(0.09)$ \\
\hline Demographic controls & Yes & Yes \\
$\mathrm{R}^{2}$ & 0.032 & 0.064 \\
N observations & 1478 & 720 \\
\hline Note: Demographic controls include log of household income per \\
capita, employment status, urban/rural area, age, age squared, \\
gender, and marital status. We report OLS estimates based on \\
population weights. Standard errors are in parentheses. ${ }^{*} p<$ \\
$0.10,{ }^{* *} p<0.05,{ }^{* * *} p<0.01$
\end{tabular}

In addition to direct treatment effects on consumer sentiment, there could be indirect effects via the variables affecting sentiment discussed in the previous section. This is what we test next, starting with the effects of our treatments on macroeconomic expectations (see Table 5). In neither country do we find significant treatment effects on inflation expectations. However, as Model (3) in Table 5 shows, Vietnamese consumers treated with either the government reaction or the public reaction treatment are $3 \%$ or $5 \%$, respectively, less likely to expect unemployment to increase a lot compared to the non-treated control group. This suggests that both treatments are regarded as good news, thus causing consumers to become more optimistic about the labor market outlook. Moreover, Vietnamese consumers receiving the government reaction treatment are $3 \%$ more likely to expect GDP growth to increase a lot than are consumers in the control group (see Model (5) in Table 5), which is also in line with a "good news" effect. In contrast, the same treatments have no significant effects on macroeconomic expectations in the Thai sample. Overall, the treatment effects suggest that providing information about other consumers' beliefs, in this case about the appropriateness ratings of the government's/general public's reaction to COVID-19, can have important implications for consumers' macroeconomic expectations. Since we show in the previous section that both unemployment and GDP expectations are important drivers of consumer sentiment, the treatment effects could also have indirect effects on consumer sentiment. Interestingly, this result holds only for Vietnam, where the presented information highlighted that Viet- 
namese respondents in the other survey agreed most with their government's policies in a cross-country comparison. This "good news" seems to have been interpreted as a positive signal for future macroeconomic development. While the point estimates for the Thai sample suggest opposite effects, the "bad news" that Thai respondents disagree most with their government's policies compared to people in other countries is not strong enough to generate significantly negative effects.

Table 5: Marginal Effects of Information Treatments on Macroeconomic Expectations

\begin{tabular}{lcccccc}
\hline & \multicolumn{2}{c}{$\pi^{e}$} & \multicolumn{2}{c}{$u^{e}$} & $y^{e}$ \\
& $(1)$ & $(2)$ & $(3)$ & $(4)$ & $(5)$ & $(6)$ \\
& VN & TL & VN & TL & VN & TL \\
\hline \multirow{2}{*}{ Government reaction } & 0.02 & 0.03 & $-0.03^{*}$ & 0.06 & $0.03^{* *}$ & -0.002 \\
& $(0.02)$ & $(0.03)$ & $(0.02)$ & $(0.04)$ & $(0.01)$ & $(0.01)$ \\
Public reaction & 0.009 & 0.009 & $-0.05^{* * *}$ & 0.02 & 0.02 & -0.008 \\
& $(0.02)$ & $(0.03)$ & $(0.02)$ & $(0.04)$ & $(0.01)$ & $(0.01)$ \\
\hline Demographic controls & Yes & Yes & Yes & Yes & Yes & Yes \\
Pseudo R & 0.008 & 0.008 & 0.007 & 0.014 & 0.009 & 0.020 \\
N observations & 1478 & 720 & 1478 & 720 & 1478 & 720 \\
\hline
\end{tabular}

Note: Demographic controls include log of household income per capita, employment status, urban/rural area, age, age squared, gender, and marital status. We report marginal effects for choosing the highest answer category from ordered probit estimations based on population weights. Standard errors are in parentheses. ${ }^{*} p<0.10,{ }^{* *} p<0.05,{ }^{* * *} p<0.01$

Finally, Table 6 presents the treatment effects on concerns related to COVID-19. In the Vietnamese sample, the government reaction treatment reduces by $9 \%$ the likelihood of respondents answering that they are very concerned about the impact of the pandemic on the job security of household members (see Model (3) of Table 6). This reinforces our earlier interpretation that respondents tend to view this treatment as good news. The public reaction treatment has a similar effect and reduces by $9 \%$ and 10\%, respectively, the likelihood of respondents stating that they are very concerned about their job security or the financial situation of their household (see Models (3) and (5) of Table 6). Moreover, those who receive the public reaction treatment are $7 \%$ less likely to report that they are very concerned about their health, although the effect is only marginally significant at the $10 \%$ level (see Model (1) of Table 6). In the Thai sample, the public reaction treatment increases by $9 \%$ the likelihood of respondents stating that they are very concerned about the financial situation of the household, but, again, the effect is only marginally significant at $10 \%$. Generalizing this evidence suggests that the public reaction treatment is interpreted very differently in the two countries even though the provided information was quite similar.

In the Appendix, we re-estimate all treatment effects using the full sample based on the assumption that respondents can be categorized as neutral when they answer "don't know" or "do not form opinions" to our main survey questions. Tables A2-A5 demonstrate 
that our results generally remain unchanged. A notable exception can be found in the Thai sample, where, surprisingly, the government reaction information treatment reduces Thai consumers' concerns about their financial situation and the economy in general (see Table A5).

In summary, even though there is only little direct evidence of information treatment effects on consumer sentiment, we do find, in the Vietnamese sample, significant and economically meaningful treatment effects on some macroeconomic expectations and on personal concerns related to the pandemic. In particular, the government reaction and public reaction treatments cause respondents in Vietnam to become more optimistic compared to the control group, and thus the information provided seems to be viewed as good news. Note, however, that there are no treatment effects at all in the Thai baseline sample, except for the public reaction treatment effect on respondents' concerns about their household financial situation. We can exclude the possibility that this is simply a matter of different sample sizes; rather, it seems that the information provided is interpreted as bad news in Thailand and that the negative influence on sentiment is weaker than the positive effect found in the Vietnamese sample.

Table 6: Marginal Effects of Information Treatments on Concerns Due to COVID-19

\begin{tabular}{lccccccccc}
\hline & \multicolumn{2}{c}{ concern_health } & \multicolumn{2}{c}{ concern_job } & \multicolumn{2}{c}{ concern_finance } & \multicolumn{2}{c}{ concern_econ } \\
& $(1)$ & $(2)$ & $(3)$ & $(4)$ & $(5)$ & $(6)$ & $(7)$ & $(8)$ \\
& VN & TL & VN & TL & VN & TL & VN & TL \\
\hline \multirow{2}{*}{ Government reaction } & -0.05 & -0.02 & $-0.09^{* *}$ & -0.05 & -0.07 & -0.07 & -0.02 & -0.02 \\
& $(0.04)$ & $(0.05)$ & $(0.04)$ & $(0.05)$ & $(0.04)$ & $(0.05)$ & $(0.04)$ & $(0.05)$ \\
Public reaction & $-0.07^{*}$ & 0.06 & $-0.09^{* *}$ & 0.06 & $-0.1^{* *}$ & $0.09^{*}$ & -0.05 & 0.03 \\
& $(0.04)$ & $(0.05)$ & $(0.04)$ & $(0.05)$ & $(0.04)$ & $(0.05)$ & $(0.04)$ & $(0.05)$ \\
\hline Demographic controls & Yes & Yes & Yes & Yes & Yes & Yes & Yes & Yes \\
Pseudo R & 0.019 & 0.024 & 0.033 & 0.034 & 0.027 & 0.056 & 0.012 & 0.055 \\
N observations & 1478 & 720 & 1478 & 720 & 1478 & 720 & 1478 & 720 \\
\hline
\end{tabular}

Note: Demographic controls include log of household income per capita, employment status, urban/rural area, age, age squared, gender, and marital status. We report marginal effects for choosing the highest answer category from ordered probit estimations with population weights. Standard errors are in parentheses. ${ }^{*} p<0.10,{ }^{* *}$ $p<0.05,{ }^{* * *} p<0.01$ 


\subsection{Heterogeneity Conditioning on Respondents' Prior Assess- ment of Government Policies}

In this section, we evaluate whether there are heterogeneous treatment effects across respondents' assessment of government policies during normal times, that is, before the COVID-19 crisis. We hypothesize that conditioning on prior beliefs, "surprising" information, in the sense that the information contradicts the respondent's prior belief, will have a relatively stronger influence on consumer sentiment.

To study these heterogeneous effects, we regress consumer sentiment on an interaction term between the dummy capturing the information treatments and respondents' prior assessment of government policies, while controlling for the same set of demographic factors. Figure 4 presents the marginal effects of information treatments on consumer sentiment across different categories, together with a $90 \%$ confidence interval.

In the Vietnamese sample, the government reaction and the public reaction treatments, which are perceived as good news, significantly increase consumer sentiment among those who previously gave a poor assessment of government macroeconomic policies in normal times. By contrast, Vietnamese consumers who think the government did a fair or a good job in normal times do not significantly react to either the government reaction or the public reaction information (see Figures $4 \mathrm{a}$ and $4 \mathrm{c}$ ). The treatment effects on consumer sentiment across the categories of government assessment are significantly differently from each other in the government reaction treatment, but not in the public reaction treatment. The minority of Thai respondents stating that the government did a good job in normal times become more pessimistic after receiving the government reaction treatment, which shows that Thailand ranks lowest in terms of citizens' agreement with their government's policies during the crisis (see Figure $4 \mathrm{~b}$ ). However, the effect is statistically insignificant. ${ }^{8}$

Tables A6, A7, and A8 in the Appendix contain additional results on the heterogeneity of treatment effects on macroeconomic expectations, the assessment of and trust in government policies in dealing with COVID-19, and personal concerns due to COVID-19, respectively. Although we do not find many statistically significant effects, we do find a number of cases that are qualitatively consistent with our hypothesis that "surprising" information will significantly affect respondents' beliefs. For instance, Table A8 shows that the government reaction and public reaction treatments reduce by about $40 \%$ the likelihood of answering that unemployment will increase significantly in the next 12 months for Vietnamese consumers who thought the government did a poor job in normal times, but by only about $5 \%$ for those who thought the government did a good job. In the case of Thailand, consumers with a positive prior assessment of the government's job in normal times are $20 \%$ more likely to answer that unemployment will increase significantly when they receive the government reaction treatment.

\footnotetext{
${ }^{8}$ As shown in Figures A4 and A5 in the Appendix, our results remain roughly unchanged when using the full sample, that is, when we treat "don't know" and "no opinion" answers as neutral for our main questions or when we additionally control for respondents' current mood.
} 
Overall, our results suggest that prior beliefs may matter for the treatment effects on consumer sentiment and that only those consumers "surprised" by the information change their sentiment in a significant way, consistent with the results in Coibion et al. (2020b). Moreover, the point estimates suggest sizable treatment effects on consumer sentiment in these cases of about 1.2 s.d. in the government reaction treatment and 0.8 s.d. in the public reaction treatment. Note, however, that the treatment effects differ significantly across groups only in the government reaction treatment and that we encounter an asymmetric reaction between our sample countries.

Figure 4: The Effect of Information Treatments on Consumer Sentiment Conditional on Prior Assessment of Government Macroeconomic Policies in Normal Time with 90\% Confidence Intervals

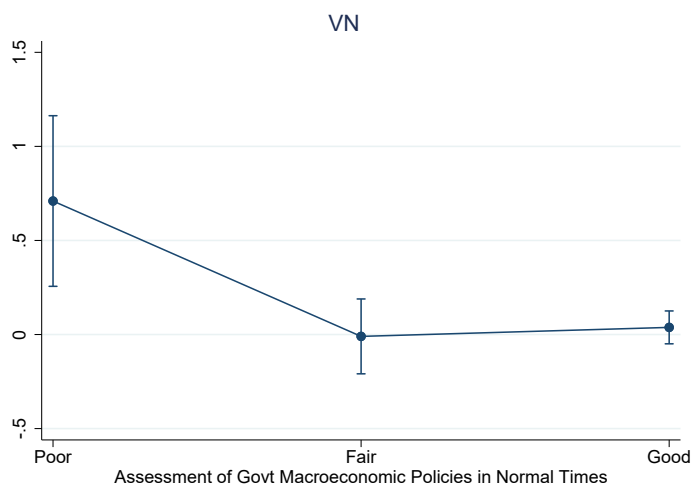

(a) Government reaction

$\mathrm{VN}$

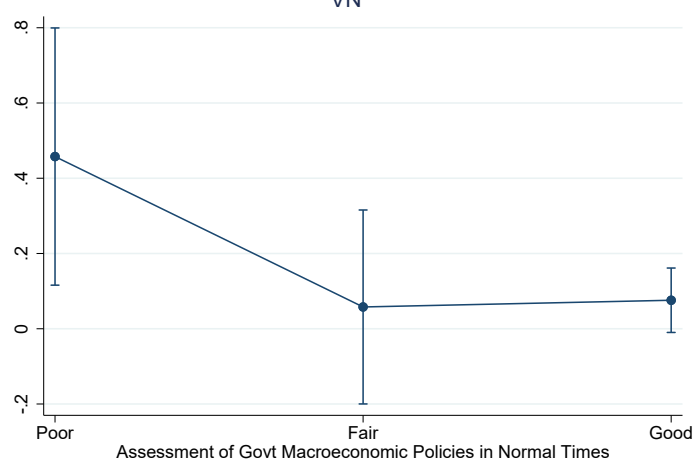

(c) Public reaction

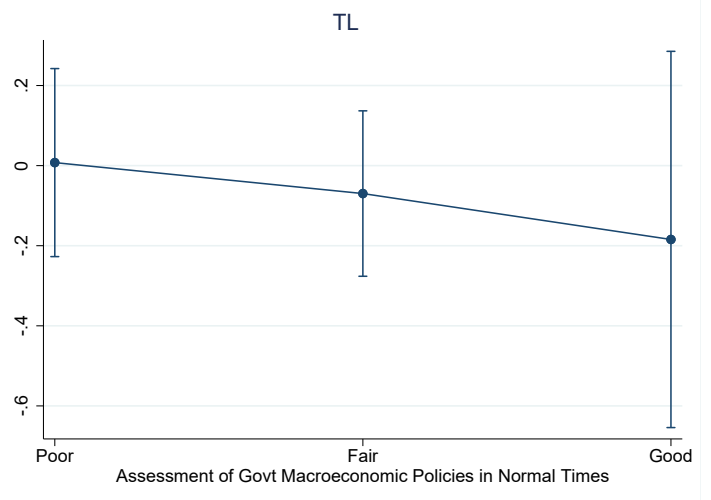

(b) Government reaction

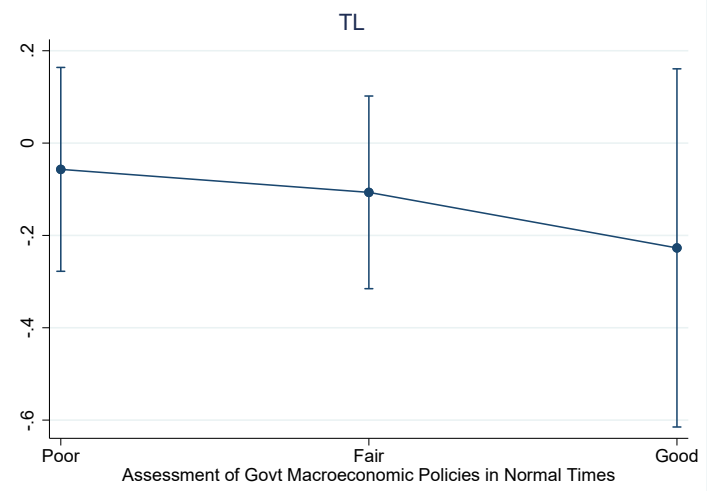

(d) Public reaction

\section{Discussion and Concluding Remarks}

In this paper, we use the COVID-19 crisis as a case study to evaluate the effect of information about others' beliefs on the appropriateness of the government's and the general public's reaction on consumer sentiment in Thailand and Vietnam. Using an RCT information experiment in online surveys conducted after the first easing of lockdown measures 
in May and December 2020, we use cross-country variation in average appropriateness ratings among the countries. In our government reaction treatment, Thailand has the lowest approval rating of the government's reaction, whereas Vietnam has the highest. By contrast, approval rates for the general public's reaction in the public reaction treatment are similar for the two countries. Thus, the two information treatments allow testing for an effect of others' beliefs on the respondents' own beliefs.

We find that information on average beliefs of others about the appropriateness of the government's reaction does not affect respondents' own appropriateness rating or trust in the government. However, we do find significant treatment effects on consumer sentiment and on some of the variables influencing it. Interestingly, all significant treatment effects are found for the Vietnamese sample and suggest that both treatments are perceived as good news by Vietnamese consumers. Receiving these treatments causes consumers to expect lower unemployment and higher GDP growth and reduces COVID-19-related concerns about job security or household financial situation. In the case of the public reaction treatment, we also find a direct positive effect on consumer sentiment. Overall, these results indicate that the framing of information about others' beliefs may affect consumers' own beliefs and that consumers react more strongly to good news than they do to bad. The outcome of a second survey wave seven months after the first survey suggests that information treatment effects are generally short-lived and the information related to a government's reaction to the pandemic was more powerful at the beginning of the pandemic. However, we also find evidence that treatments included in the earlier survey seem to cause effects on people's attitudes and assessments in the later survey, although they did not have a significant impact at the time of the treatment. This suggests that the temporal effects of information treatments may be more complex than previously thought, which may be an interesting area for further research.

In addition, our results suggest that information treatments about other consumers' beliefs can significantly and strongly affect consumer sentiment when they "contradict" respondents' priors. As a proxy for this prior, we use the assessment of the government's economic policies during normal times, that is, before the COVID-19 pandemic. Whereas we find only moderately sized treatment effects ranging from 0.15 to 0.3 s.d. for the significant effects in the first part of our analysis, we now discover notable treatment effects ranging from 0.8 to 1 s.d. Thus, these effects are not only statistically significant, they also have potentially important economic consequences. In the Thai sample, those who previously gave a good assessment of their government's policies during normal times show somewhat more pessimistic sentiment after receiving either treatment, even though the effect is not statistically significant. More generally, due to estimation uncertainty, the estimated treatment effects across categories of previous government assessment are significantly different only in the government reaction treatment. To summarize, it seems that the effect of information about others' beliefs on consumer sentiment is particularly strong when the information goes against respondents' prior views. 
Overall, our results show that consumer sentiment remains affected by the COVID-19 crisis even after the strict lockdown phase, which ended before May 2020 in both countries. Note that our two sample countries were affected relatively mildly by the pandemic and it seems plausible to assume that the effects are likely much larger in countries hit more strongly. The different results in the Vietnamese and the Thai sample serve as a forceful reminder that generalizing results from one country - even when they are obtained through RCTs - may be problematic, as external reliability is not guaranteed.

\section{References}

Ahmed, M. I. and S. P. Cassou (2016). Does Consumer Confidence Affect Durable Goods Spending during Bad and Good Economic Times Equally? Journal of Macroeconomics 50, $86-97$.

Andersen, A., E. Hansen, N. Johannesen, and A. Sheridan (2020). Consumer Responses to the COVID-19 Crisis: Evidence from Bank Account Transaction Data. CEPR Discussion Paper 14809.

Bachmann, R., T. O. Berg, and E. R. Sims (2015). Inflation Expectations and Readiness to Spend: Cross-Sectional Evidence. American Economic Journal: Economic Policy $\underline{7}(1)$, $1-35$.

Bachmann, R., S. Elstner, and E. R. Sims (2013). Uncertainty and economic activity: Evidence from business survey data. American Economic Journal: Macroeconomics $5(2)$, 217-249.

Bachmann, R. and E. R. Sims (2012). Confidence and the Transmission of Government Spending Shocks. Journal of Monetary Economics 59(3), $235-249$.

Baker, S. R., R. Farrokhnia, S. Meyer, M. Pagel, and C. Yannelis (2020). How Does Household Spending Respond to an Epidemic? Consumption During the 2020 COVID19 Pandemic. Covid Economics (18).

Barron, K. (2021). Belief Updating: Does the 'Good-News, Bad-News' Asymmetry Extend to Purely Financial Domains? Experimental Economics (24), 31-58.

Barsky, R. B. and E. R. Sims (2012). Information, Animal Spirits, and the Meaning of Innovations in Consumer Confidence. American Economic Review 102(4), 1343-77.

Binder, C. (2020). Coronavirus Fears and Macroeconomic Expectations. Review of Economics and Satistics (forthcoming).

Bowman, D., D. Minehart, and M. Rabin (1999). Loss aversion in a consumption-savings model. Journal of Economic Behavior and Organization 38(2), 155-178. 
Carroll, C. D., J. C. Fuhrer, and D. W. Wilcox (1994). Does Consumer Sentiment Forecast Household Spending? If so, why? American Economic Review 84(5), 1397-1408.

Carvalho, B. P., S. Peralta, and J. Pereira (2020). What and How did People Buy during the Great Lockdown? Evidence from Electronic Payments. Covid Economics (28).

Chen, S.-S. (2011). Lack of Consumer Confidence and Stock Returns. Journal of Empirical Finance $\underline{18}(2), 225-236$.

Christelis, D., D. Georgarakos, T. Jappelli, and G. Kenny (2020). The Covid-19 Crisis and Consumption: Survey Evidence From Six EU Countries. ECB Working Paper 2507.

Chronopoulos, D. K., M. Lukas, and J. O. Wilson (2020). Consumer Spending Responses to the COVID-19 Pandemic: An Assessment of Great Britain. Covid Economics (34).

Coibion, O., D. Georgarakos, Y. Gorodnichenko, and M. van Rooij (2019). How Does Consumption Respond to News about Inflation? Field Evidence from a Randomized Control Trial. NBER Working Paper 26106.

Coibion, O., Y. Gorodnichenko, and M. Weber (2020a). Does Policy Communication During COVID work? CESifo Working Paper 8369.

Coibion, O., Y. Gorodnichenko, and M. Weber (2020b). Political Polarization and Expected Economic Outcomes. NBER Working Paper 28044.

Coibion, O., Y. Gorodnichenko, and M. Weber (2020c). The Cost of the COVID-19 Crisis: Lockdowns, Macroeconomic Expectations, and Consumer Spending. NBER Working Paper 27141.

Coutts, A. (2019). Good News and Bad News Are Still News: Experimental Evidence on Belief Updating. Experimental Economics (22), 369-395.

Crump, R. K., S. Eusepi, A. Tambalotti, and T. G. (2015). Subjective Intertemporal Substitution. Federal Reserve Bank of New York Staff Reports 734.

D'Acunto, F., D. Hoang, and M. Weber (2016). The Effect of Unconventional Fiscal Policy on Consumption Expenditure. NBER Working Paper 22563.

Dang, H.-A. H. and L. T. Giang (2020). Turning Vietnam's COVID-19 Success into Economic Recovery: A Job-Focused Analysis of Individual Assessments on Their Finance and the Economy. Global Labor Organization Discussion Paper 566.

Dees, S. and P. Soares Brinca (2013). Consumer Confidence as a Predictor of Consumption Spending: Evidence for the United States and the Euro Area. International $\underline{\text { Economics }} \underline{134}, 1-14$. 
Dölitzsch, C. (2020, March). Global Study about COVID-19: Dalia Assesses How the World Ranks Their Governments' Response to the Pandemic. Dalia Report.

Dräger, L. and G. Nghiem (2020). Are Consumers' Spending Decisions in Line With an Euler Equation? Review of Economics and Statistics (forthcoming).

Duca-Radu, I., G. Kenny, and A. Reuter (2021). Inflation Expectations, Consumption and The Lower Bound: Micro Evidence From A Large Multi-country Survey. Journal $\underline{\text { of Monetary Economics }} \underline{118}, 120-134$.

Eil, D. and J. Rao (2011). The Good News-Bad News Effect: Asymmetric Processing of Objective Information about Yourself. American Economic Journal: Microeconomics (3), 114-138.

Fetzer, T., L. Hensel, J. Hermle, and C. Roth (2020). Coronavirus Perceptions and Economic Anxiety. Review of Economics and Statistics (forthcoming).

Fetzer, T., M. Witte, L. Hensel, J. M. Jachimowicz, J. Haushofer, A. Ivchenko, S. Caria, E. Reutskaja, C. Roth, S. Fiorin, M. Gomez, G. Kraft-Todd, F. M. Goetz, and E. Yoeli (2020a). Perceptions of an Insufficient Government Response at the Onset of the COVID-19 Pandemic are Associated with Lower Mental Well-Being. NBER Working Paper 27082.

Fetzer, T., M. Witte, L. Hensel, J. M. Jachimowicz, J. Haushofer, A. Ivchenko, S. Caria, E. Reutskaja, C. R. Roth, S. Fiorin, M. Gomez, G. Kraft-Todd, F. M. Goetz, and E. Yoeli (2020b). Global Behaviors and Perceptions in the COVID-19 Pandemic. https : //doi.org/10.31234/osf.io/3kfmh.

Hanspal, T., A. Weber, and J. Wohlfart (2020). Exposure to the COVID-19 Stock Market Crash and its Effect on Household Expectations. $\underline{\text { Review of Economics and }}$

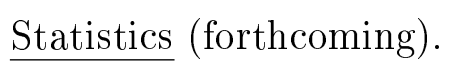

Jansen, W. and N. J. Nahuis (2003). The Stock Market and Consumer Confidence: European Evidence. Economics Letters 79(1), 89 - 98.

Kuhnen, C. M. (2014). Asymmetric Learning from Financial Information. The Journal of Finance $\underline{\operatorname{LXX}}(5), 2029-2062$.

Ludvigson, S. C. (2004). Consumer Confidence and Consumer Spending. Journal of Economic perspectives 18(2), 29-50.

Souleles, N. S. (2004). Expectations, Heterogeneous Forecast Errors, and Consumption: Micro Evidence from the Michigan Consumer Sentiment Surveys. Journal of Economic $\underline{\text { perspectives }} \underline{18}(2), 29-50$. 
Vellekoop, N. and M. Wiederholt (2019). Inflation Expectations and Choices of Household. SAFE Working Paper 250. 


\section{A Appendix}

\section{A.1 Macroeconomic Development in Thailand and Vietnam}

Figure A1: Recent GDP growth and Inflation Development in Thailand and Vietnam

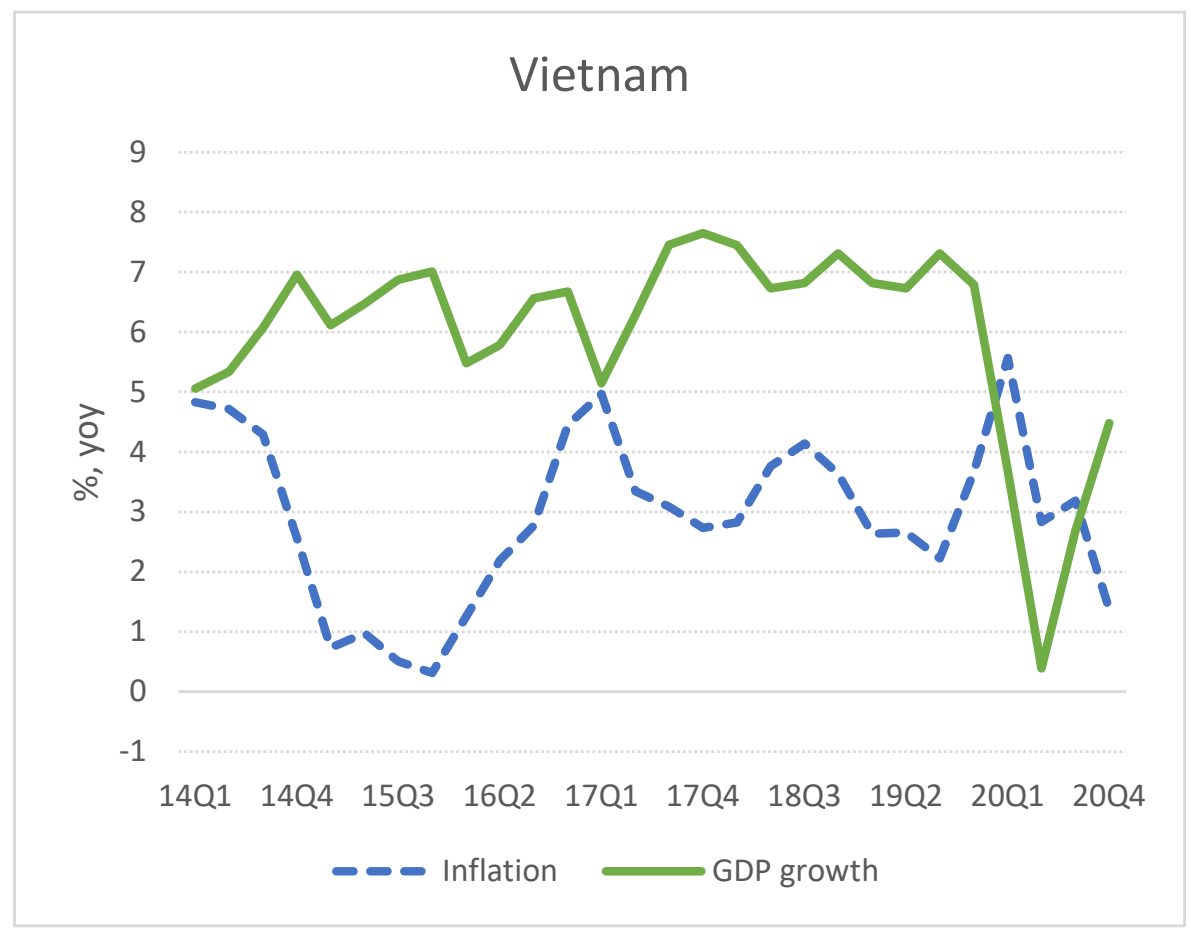

(a) Vietnam (Source: General Statistical Office of Vietnam.)

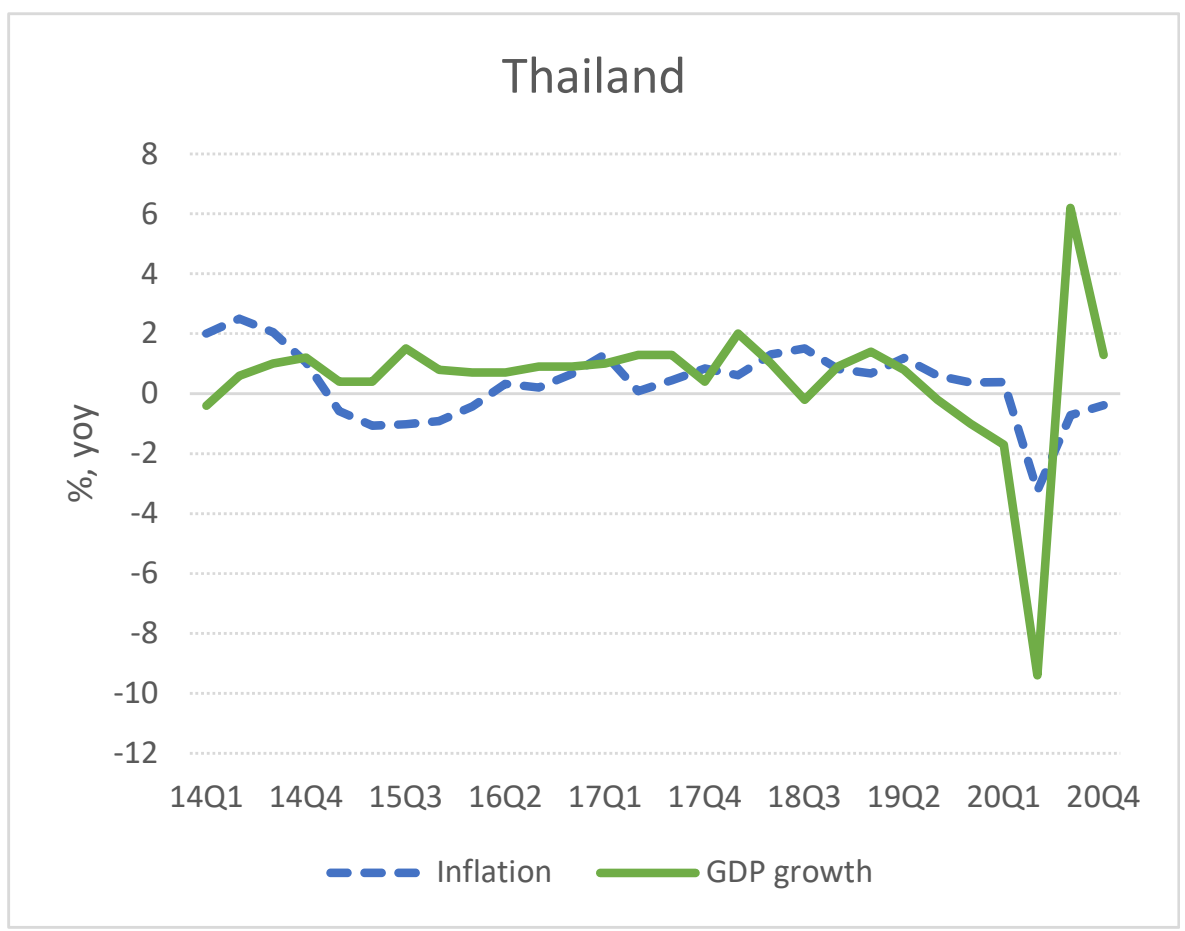

(b) Thailand (Source: Bank of Thailand) 
Figure A2: Trust in Scientific Research/Scientists

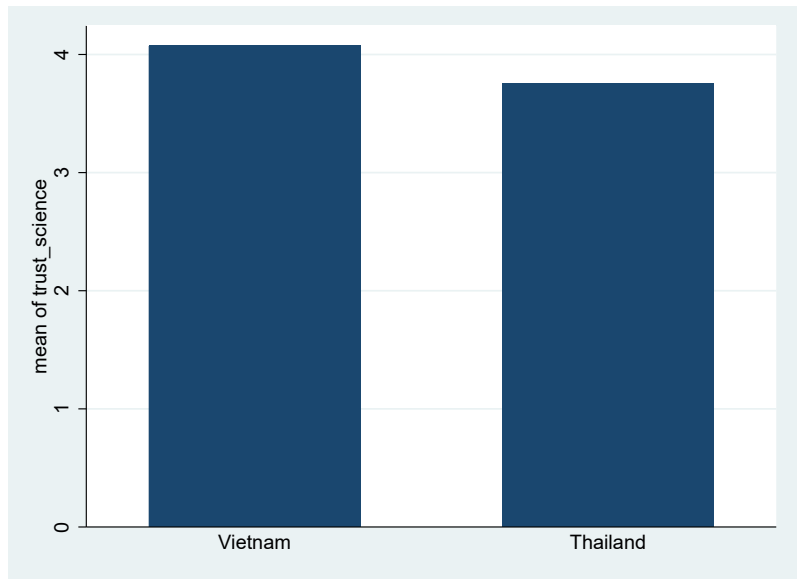

Figure A3: Assessment of Information Treatments

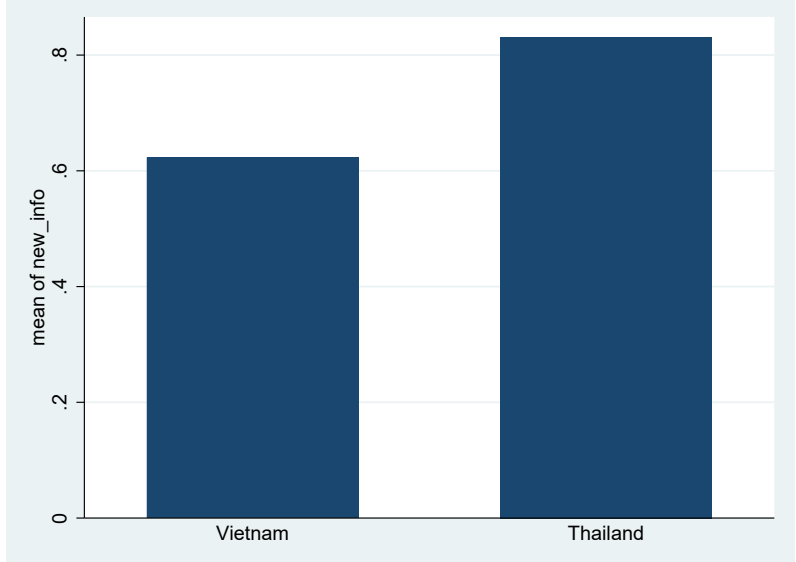

(a) Government reaction (New vs. Old)

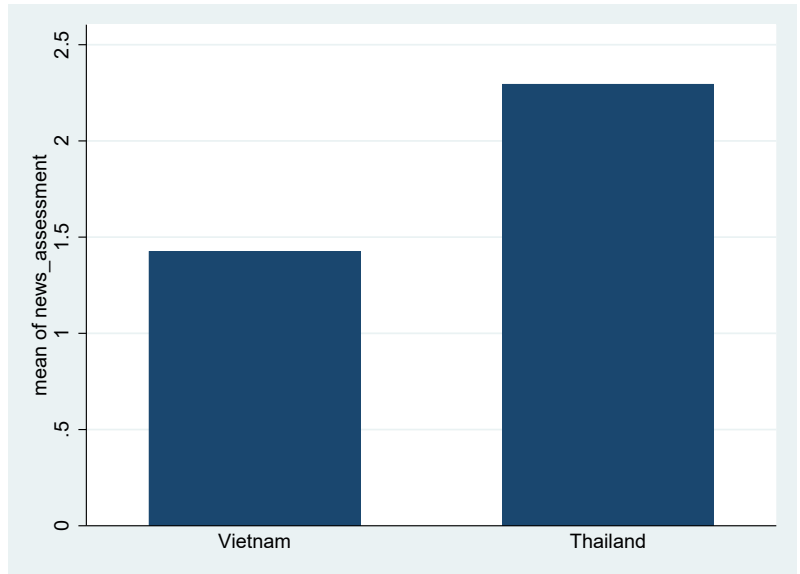

(c) Government reaction (Good, Neutral, Bad)

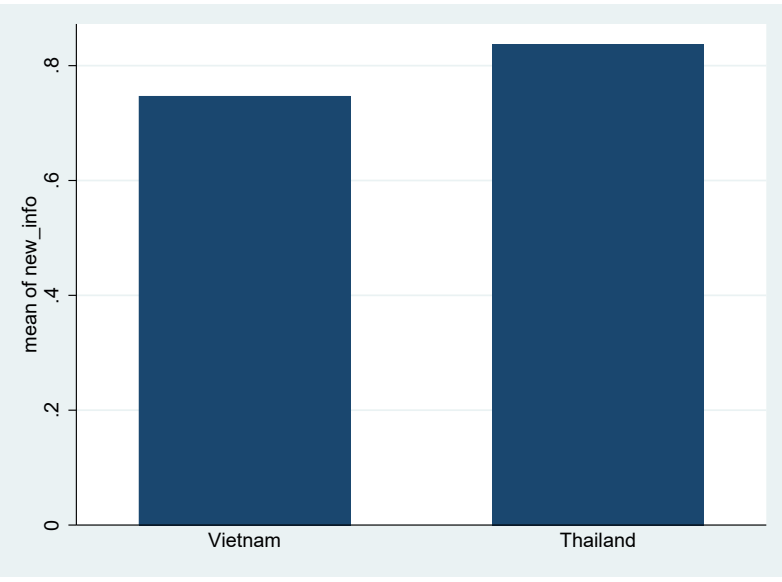

(b) Public reaction (New vs. Old)

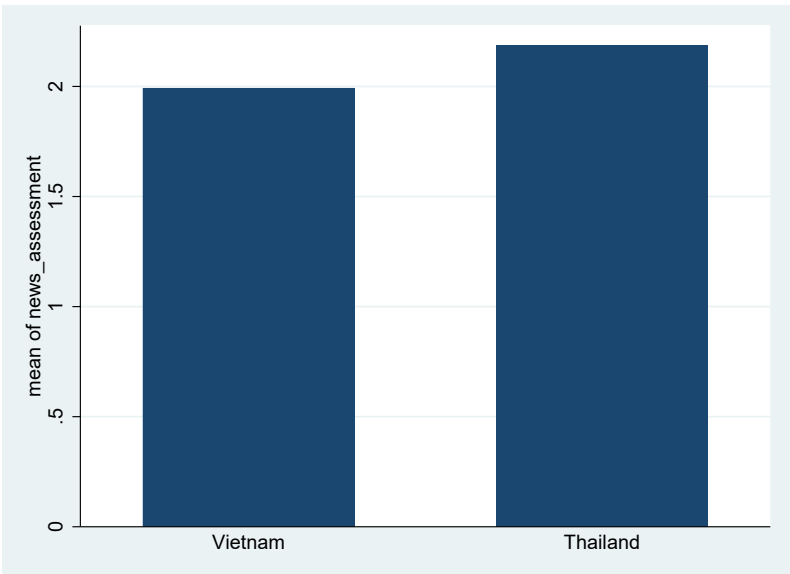

(d) Public reaction (Good, Neutral, Bad) 


\section{A.2 Robustness Checks}

In this section, we re-estimate the baseline results using the full sample and assuming that respondents expect no change, neither trust/distrust, or are not concerned at all when they do not know the answer or do have opinions about the survey questions used for the individual index of consumer sentiment and the regressors in Table 2. We thus have a full sample of 1,980 observations in Vietnam and 1,320 observations in Thailand. Overall, most of our baseline results remain unchanged, except Table A5 shows that in the Thai sample, the government reaction information treatment, which is framed as bad news, reduces Thai consumers' concerns about their financial situation and the economy in general. 
Table A1: Consumer Sentiment: Control Group, Full sample

\begin{tabular}{|c|c|c|c|c|}
\hline & $\begin{array}{c}\text { OLS M } \\
(1) \\
\text { VN }\end{array}$ & $\begin{array}{l}\text { Sample } \\
\text { (2) } \\
\text { TL }\end{array}$ & $\begin{array}{l}\text { Panel F } \\
(3) \\
\text { VN }\end{array}$ & $\begin{array}{l}\text { d Effects } \\
(4) \\
\text { TL }\end{array}$ \\
\hline$\pi^{e}$ & $\begin{array}{c}0.06^{* * *} \\
(0.02)\end{array}$ & $\begin{array}{c}0.05 \\
(0.04)\end{array}$ & $\begin{array}{c}0.08^{* * *} \\
(0.03)\end{array}$ & $\begin{array}{c}0.04 \\
(0.04)\end{array}$ \\
\hline$u^{e}$ & $\begin{array}{l}-0.03 \\
(0.02)\end{array}$ & $\begin{array}{l}-0.06^{*} \\
(0.03)\end{array}$ & $\begin{array}{l}0.006 \\
(0.04)\end{array}$ & $\begin{array}{l}-0.06^{*} \\
(0.04)\end{array}$ \\
\hline$y^{e}$ & $\begin{array}{l}0.2^{* * *} \\
(0.02)\end{array}$ & $\begin{array}{l}0.2^{* * *} \\
(0.04)\end{array}$ & $\begin{array}{l}0.2^{* * *} \\
(0.04)\end{array}$ & $\begin{array}{l}0.2^{\text {*** }} \\
(0.05)\end{array}$ \\
\hline govt_assess_normal_times & $\begin{array}{c}0.09^{*} \\
(0.05)\end{array}$ & $\begin{array}{l}0.2^{\text {*** }} \\
(0.07)\end{array}$ & $\begin{array}{c}0.04 \\
(0.06)\end{array}$ & $\begin{array}{l}0.4^{* * *} \\
(0.08)\end{array}$ \\
\hline govt_covid_appropriate & $\begin{array}{l}-0.04 \\
(0.07)\end{array}$ & $\begin{array}{l}-0.10 \\
(0.09)\end{array}$ & $\begin{array}{c}0.1 \\
(0.09)\end{array}$ & $\begin{array}{c}0.03 \\
(0.12)\end{array}$ \\
\hline govt_trust_covid_health & $\begin{array}{c}0.01 \\
(0.03)\end{array}$ & $\begin{array}{c}0.04 \\
(0.04)\end{array}$ & $\begin{array}{l}-0.02 \\
(0.06)\end{array}$ & $\begin{array}{l}-0.1^{* *} \\
(0.05)\end{array}$ \\
\hline govt_trust_covid_econ & $\begin{array}{c}0.08^{* * *} \\
(0.03)\end{array}$ & $\begin{array}{l}0.07^{*} \\
(0.04)\end{array}$ & $\begin{array}{r}-0.006 \\
(0.04)\end{array}$ & $\begin{array}{c}0.2^{* *} \\
(0.07)\end{array}$ \\
\hline concern_health & $\begin{array}{c}-0.005 \\
(0.04)\end{array}$ & $\begin{array}{l}-0.03 \\
(0.07)\end{array}$ & $\begin{array}{l}-0.04 \\
(0.08)\end{array}$ & $\begin{array}{c}-0.1 \\
(0.08)\end{array}$ \\
\hline concern_job & $\begin{array}{c}-0.07^{*} \\
(0.04)\end{array}$ & $\begin{array}{l}-0.2^{* *} \\
(0.08)\end{array}$ & $\begin{array}{l}-0.01 \\
(0.06)\end{array}$ & $\begin{array}{l}-0.3^{* *} \\
(0.11)\end{array}$ \\
\hline concern_finance concern_finance & $\begin{array}{c}-0.1^{* * *} \\
(0.04)\end{array}$ & $\begin{array}{c}-0.1 \\
(0.07)\end{array}$ & $\begin{array}{c}0.0008 \\
(0.06)\end{array}$ & $\begin{array}{l}-0.06 \\
(0.09)\end{array}$ \\
\hline concern_econ & $\begin{array}{c}0.002 \\
(0.04)\end{array}$ & $\begin{array}{c}-0.1 \\
(0.07)\end{array}$ & $\begin{array}{c}0.06 \\
(0.06)\end{array}$ & $\begin{array}{c}0.1 \\
(0.08)\end{array}$ \\
\hline $\begin{array}{l}\text { Demographic controls } \\
\mathrm{R}^{2} \\
\mathrm{~N} \text { observations }\end{array}$ & $\begin{array}{c}\text { Yes } \\
0.394 \\
660\end{array}$ & $\begin{array}{c}\text { Yes } \\
0.337 \\
440\end{array}$ & $\begin{array}{c}\text { Yes } \\
0.319 \\
416\end{array}$ & $\begin{array}{c}\text { Yes } \\
0.472 \\
380\end{array}$ \\
\hline
\end{tabular}

Note: Full sample, May 2020. Demographic controls include the log of household income per capita, employment status, urban/rural area, age, age squared, gender and marital status. We report coefficients from OLS estimations with population weights. Standard errors are in parentheses. ${ }^{*} p<0.10,{ }^{* *} p<0.05,{ }^{* * *} p<0.01$ 
Table A2: Marginal Effects of Information Treatments on Consumer Sentiment, Full sample

\begin{tabular}{lcc}
\hline & $(1)$ & $(2)$ \\
& $\mathrm{VN}$ & $\mathrm{TL}$ \\
\hline \multirow{2}{*}{ Government reaction } & 0.05 & -0.04 \\
& $(0.04)$ & $(0.07)$ \\
Public reaction & 0.06 & -0.09 \\
& $(0.04)$ & $(0.07)$ \\
\hline Demographic controls & Yes & Yes \\
$\mathrm{R}^{2}$ & 0.035 & 0.043 \\
N observations & 1980 & 1320 \\
\hline
\end{tabular}

Note: Full sample, May 2020. Demographic controls include log of household income per capita, employment status, urban/rural area, age, age squared, gender, and marital status. We report OLS estimates based on population weights. Standard errors are in parentheses. ${ }^{*} p<0.10,{ }^{* *}$ $p<0.05,{ }^{* * *} p<0.01$

Table A3: Marginal Effects of Information Treatments on Macroeconomic Expectations, Full Sample

\begin{tabular}{lcccccc}
\hline & \multicolumn{2}{c}{$\pi^{e}$} & \multicolumn{2}{c}{$u^{e}$} & $y^{e}$ \\
& $(1)$ & $(2)$ & $(3)$ & $(4)$ & $(5)$ & $(6)$ \\
& VN & TL & VN & TL & VN & TL \\
\hline \multirow{2}{*}{ Government reaction } & 0.02 & 0.004 & $-0.03^{* *}$ & 0.03 & $0.03^{* *}$ & -0.003 \\
& $(0.01)$ & $(0.02)$ & $(0.02)$ & $(0.03)$ & $(0.01)$ & $(0.01)$ \\
Public reaction & 0.007 & -0.02 & $-0.04^{* * *}$ & 0.02 & 0.006 & 0.001 \\
& $(0.01)$ & $(0.03)$ & $(0.02)$ & $(0.03)$ & $(0.01)$ & $(0.01)$ \\
\hline Demographic controls & Yes & Yes & Yes & Yes & Yes & Yes \\
Pseudo R & 0.007 & 0.012 & 0.005 & 0.009 & 0.007 & 0.010 \\
N observations & 1980 & 1320 & 1980 & 1320 & 1980 & 1320 \\
\hline
\end{tabular}

Note: Full sample May 2020. Demographic controls include log of household income per capita, employment status, urban/rural area, age, age squared, gender, and marital status. We report marginal effects for choosing the highest answer category from ordered probit estimations based on population weights. Standard errors are in parentheses. ${ }^{*} p<0.10,{ }^{* *}$ $p<0.05,{ }^{* * *} p<0.01$ 


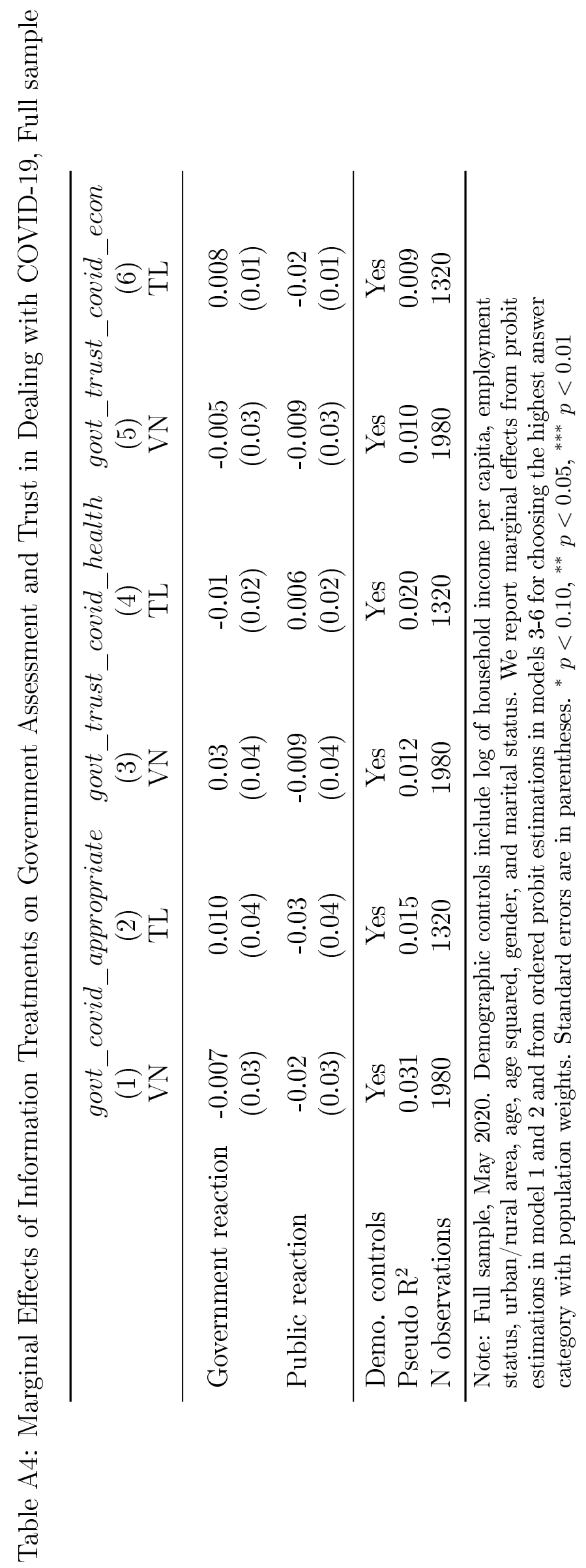


Table A5: Marginal Effects of Information Treatments on Concerns Due to COVID-19, Full sample

\begin{tabular}{lccccccccc}
\hline & \multicolumn{2}{c}{ concern_health } & \multicolumn{2}{c}{ concern } & job & \multicolumn{2}{c}{ concern_finance } & \multicolumn{2}{c}{ concern_econ } \\
& $(1)$ & $(2)$ & $(3)$ & $(4)$ & $(5)$ & $(6)$ & $(7)$ & $(8)$ \\
& VN & TL & VN & TL & VN & TL & VN & TL \\
\hline \multirow{2}{*}{ Government reaction } & -0.05 & -0.04 & $-0.10^{* * *}$ & -0.01 & $-0.09^{* *}$ & $-0.09^{* *}$ & -0.03 & $-0.1^{* * *}$ \\
& $(0.03)$ & $(0.03)$ & $(0.04)$ & $(0.04)$ & $(0.04)$ & $(0.04)$ & $(0.04)$ & $(0.04)$ \\
Public reaction & $-0.06^{*}$ & 0.003 & $-0.08^{* *}$ & 0.03 & $-0.08^{* *}$ & -0.02 & -0.04 & -0.04 \\
& $(0.03)$ & $(0.04)$ & $(0.04)$ & $(0.04)$ & $(0.04)$ & $(0.04)$ & $(0.03)$ & $(0.04)$ \\
\hline Demographic controls & Yes & Yes & Yes & Yes & Yes & Yes & Yes & Yes \\
Pseudo R & 0.017 & 0.041 & 0.031 & 0.020 & 0.023 & 0.031 & 0.006 & 0.045 \\
N observations & 1980 & 1320 & 1980 & 1320 & 1980 & 1320 & 1980 & 1320 \\
\hline
\end{tabular}

Note: Full sample, May 2020. Demographic controls include log of household income per capita, employment status, urban/rural area, age, age squared, gender, and marital status. We report marginal effects for choosing the highest answer category from ordered probit estimations based on population weights. Standard errors are in parentheses. ${ }^{*} p<0.10,{ }^{* *} p<0.05,{ }^{* * *} p<0.01$ 
Figure A4: The Effect of Information Treatments on Consumer Sentiment with 90\% Confidence Intervals, Full Sample

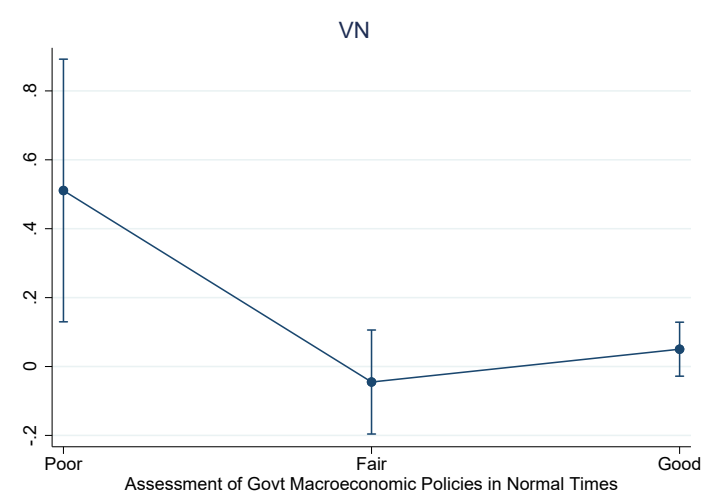

(a) Government reaction

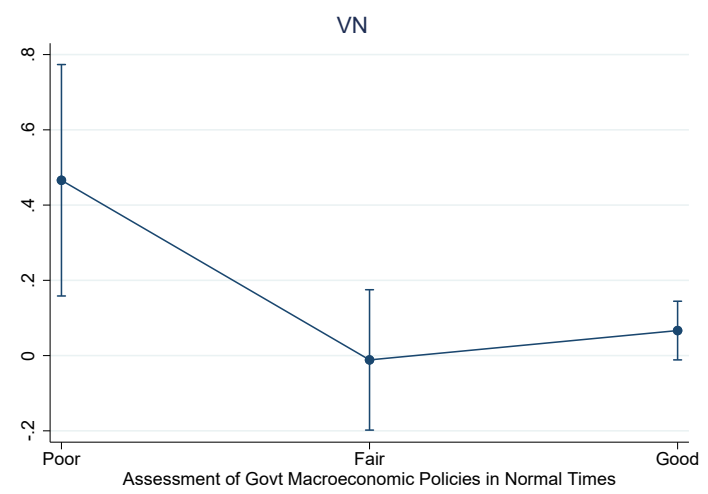

(c) Public reaction

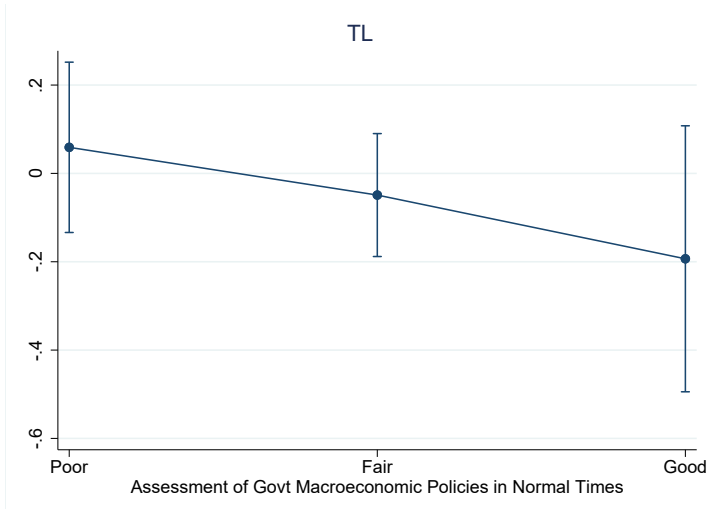

(b) Government reaction

TL

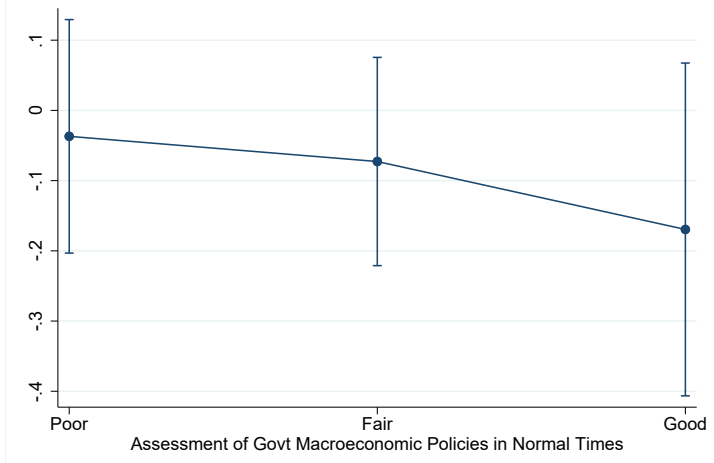

(d) Public reaction 
Figure A5: The Effect of Information Treatments on Consumer Sentiment with $90 \%$ CI Baseline Sample, Additionally Control for Current Mood

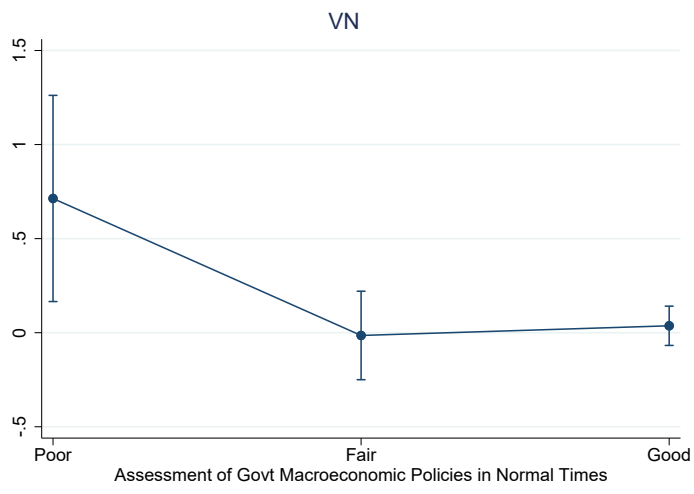

(a) Government reaction

VN

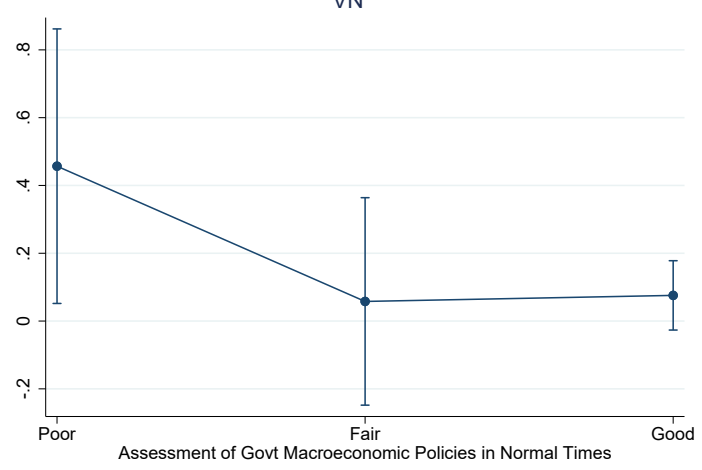

(c) Public reaction

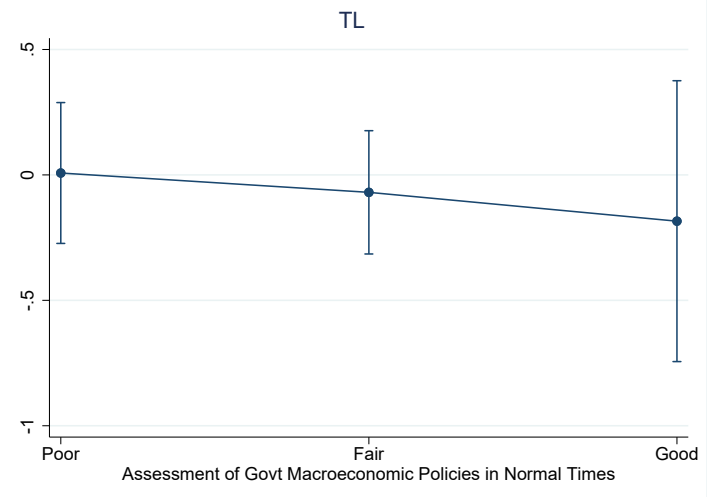

(b) Government reaction

TL

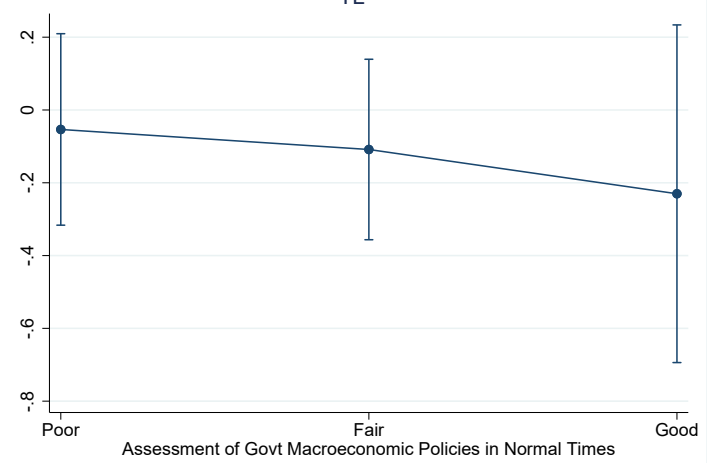

(d) Public reaction 
Table A6: Heterogeneous Marginal Effects of Information Treatments on Macroeconomic Expectations

\begin{tabular}{lcccccc}
\hline & \multicolumn{3}{c}{$\pi^{e}$} & \multicolumn{2}{c}{$u^{e}$} & $y^{e}$ \\
& $(1)$ & $(2)$ & $(3)$ & $(4)$ & $(5)$ & $(6)$ \\
& $\mathrm{VN}$ & $\mathrm{TL}$ & $\mathrm{VN}$ & $\mathrm{TL}$ & $\mathrm{VN}$ & $\mathrm{TL}$ \\
\hline govt reaction & & & & & & \\
Govt_Poor_Job & 0.1 & 0.02 & $-0.4^{* * *}$ & -0.06 & 0.04 & -0.010 \\
& $(0.08)$ & $(0.07)$ & $(0.13)$ & $(0.09)$ & $(0.04)$ & $(0.01)$ \\
Govt_Fair_Job & 0.007 & 0.01 & 0.01 & 0.07 & -0.0002 & 0.006 \\
& $(0.03)$ & $(0.04)$ & $(0.04)$ & $(0.05)$ & $(0.02)$ & $(0.02)$ \\
Govt_Good_Job & 0.02 & 0.1 & $-0.04^{*}$ & $0.2^{* *}$ & $0.03^{*}$ & 0.06 \\
& $(0.02)$ & $(0.09)$ & $(0.02)$ & $(0.09)$ & $(0.02)$ & $(0.07)$ \\
\hline Pseudo R ${ }^{2}$ & 0.010 & 0.014 & 0.017 & 0.034 & 0.026 & 0.048 \\
N observations & 994 & 484 & 994 & 484 & 994 & 484 \\
\hline \hline public reaction & & & & & & \\
Govt_Poor_Job & 0.05 & -0.008 & $-0.4^{* * *}$ & $-0.1^{*}$ & 0.03 & -0.009 \\
& $(0.08)$ & $(0.06)$ & $(0.14)$ & $(0.08)$ & $(0.02)$ & $(0.01)$ \\
Govt_Fair_Job & 0.05 & 0.001 & 0.01 & 0.07 & -0.03 & -0.003 \\
& $(0.03)$ & $(0.04)$ & $(0.04)$ & $(0.06)$ & $(0.02)$ & $(0.02)$ \\
Govt_Good_Job & 0.0008 & 0.01 & $-0.06^{* * *}$ & 0.1 & 0.03 & 0.02 \\
& $(0.02)$ & $(0.08)$ & $(0.02)$ & $(0.09)$ & $(0.02)$ & $(0.05)$ \\
\hline Pseudo R ${ }^{2}$ & 0.013 & 0.011 & 0.020 & 0.025 & 0.027 & 0.042 \\
N observations & 975 & 492 & 975 & 492 & 975 & 492 \\
\hline \hline
\end{tabular}

Note: Baseline sample May 2020. Demographic controls include log of household income per capita, employment status, urban/rural area, age, age squared, gender, and marital status. We report marginal effects for choosing the highest answer category from ordered probit estimations based on population weights. Standard errors are in parentheses. ${ }^{*} p<0.10,{ }^{* *} p<0.05,{ }^{* * *} p<0.01$ 
Table A7: Heterogeneous Marginal Effects of Information Treatments on Assessment of and Trust in Government

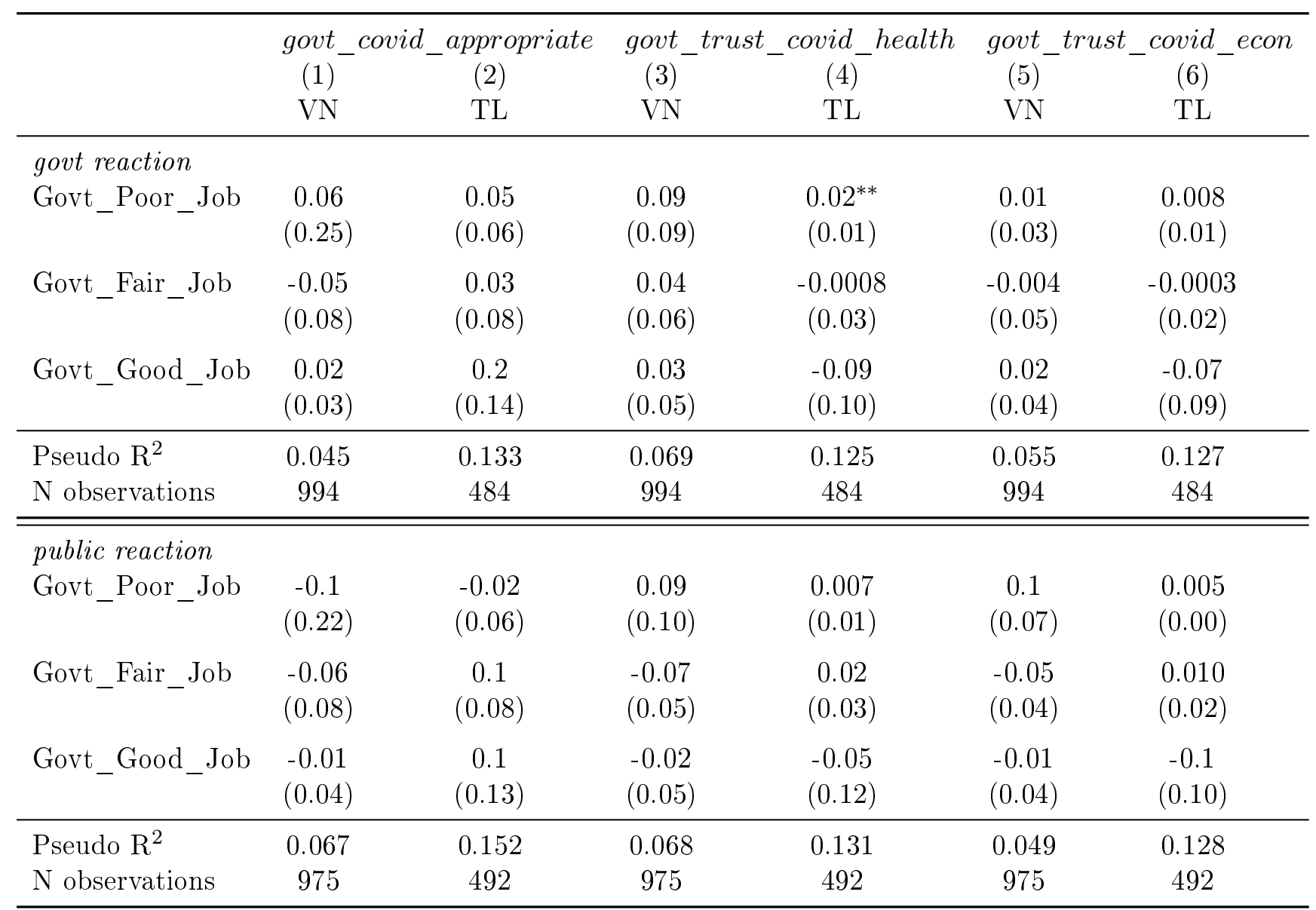

Note: Baseline sample May 2020. Demographic controls include log of household income per capita, employment status, urban/rural area, age, age squared, gender, and marital status. We report marginal effects from probit estimations in models 1 and 2 and from ordered probit estimations in models 3-6 for choosing the highest answer category with population weights. Standard errors are in parentheses. * $p<0.10,{ }^{* *} p<0.05,{ }^{* * *} p<0.01$ 
Table A8: Heterogeneous Marginal Effects of Information Treatments on Concerns Due to COVID-19

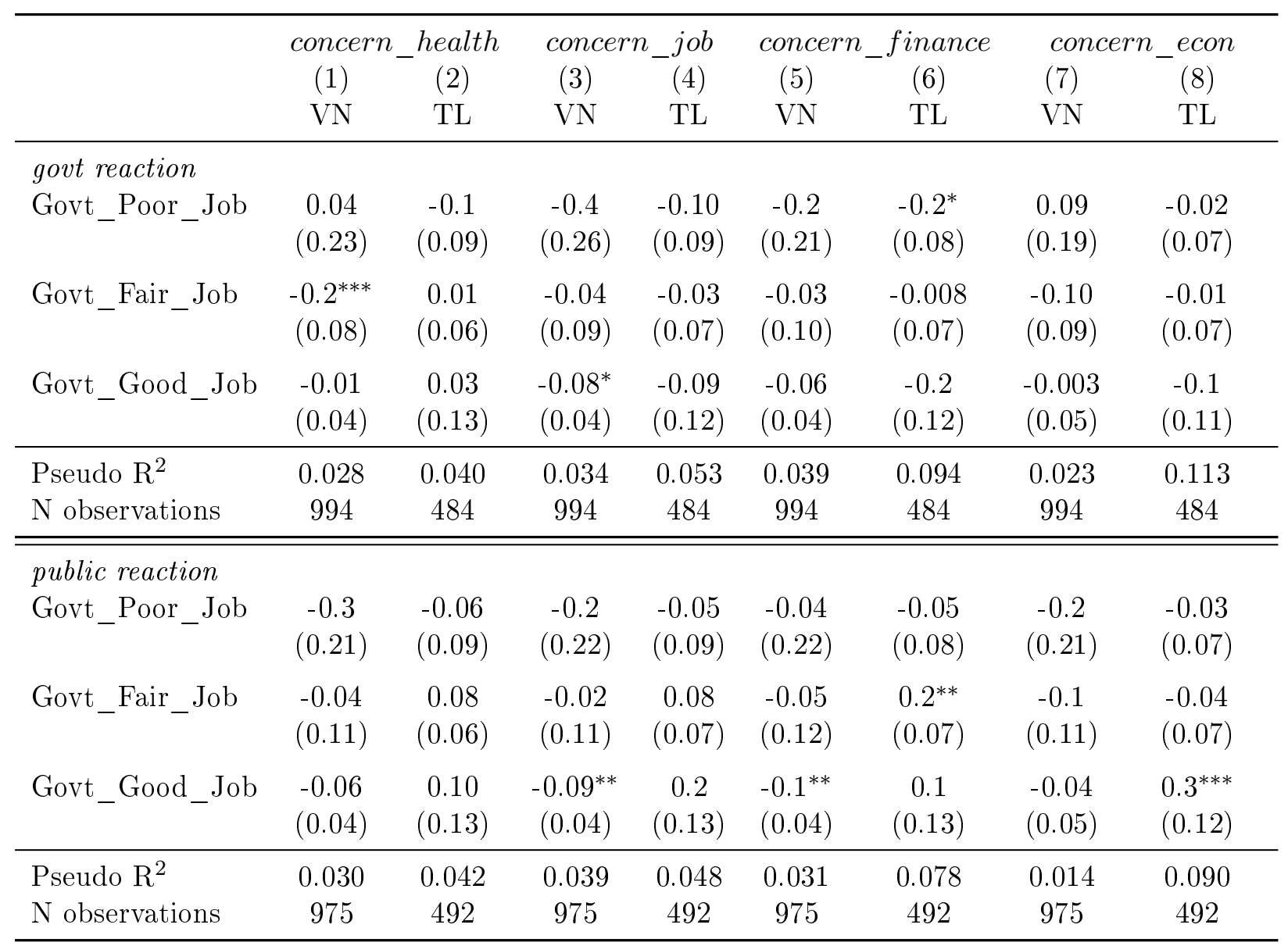

Note: Baseline sample May 2020. Demographic controls include log of household income per capita, employment status, urban/rural area, age, age squared, gender, and marital status. We report marginal effects for choosing the highest answer category from ordered probit estimations with population weights. Standard errors are in parentheses. ${ }^{*} p<0.10,{ }^{* *} p<0.05,{ }^{* * *} p<0.01$ 
Table A9: Marginal Effects of Information Treatments on Consumer Sentiment, December 2020

\begin{tabular}{lcc}
\hline & $(1)$ & $(2)$ \\
& VN & TL \\
\hline Govt reaction May & -0.010 & -0.04 \\
& $(0.07)$ & $(0.14)$ \\
Public reaction May & 0.1 & -0.1 \\
& $(0.08)$ & $(0.14)$ \\
Govt reaction Dec & 0.03 & -0.07 \\
& $(0.08)$ & $(0.13)$ \\
Public reaction Dec & -0.09 & -0.04 \\
& $(0.07)$ & $(0.13)$ \\
\hline Demographic controls & Yes & Yes \\
$\mathrm{R}^{2}$ & 0.062 & 0.023 \\
N observations & 935 & 908 \\
\hline
\end{tabular}

Note: Second wave in December 2020. Demographic controls include log of household income per capita, employment status, urban/rural area, age, age squared, gender, and marital status. We report OLS estimates based on population weights. Standard errors are in parentheses. ${ }^{*} p<0.10,{ }^{* *} p<0.05,{ }^{* * *} p<0.01$ 
Table A10: Marginal Effects of Information Treatments on Macroeconomic Expectations, December 2020

\begin{tabular}{|c|c|c|c|c|c|c|}
\hline & \multicolumn{2}{|c|}{$\pi^{e}$} & \multicolumn{2}{|c|}{$u^{e}$} & \multicolumn{2}{|c|}{$y^{e}$} \\
\hline & (1) & $(2)$ & $(3)$ & $(4)$ & $(5)$ & $(6)$ \\
\hline & VN & TL & VN & TL & VN & $\mathrm{TL}$ \\
\hline \multirow[t]{2}{*}{ Govt reaction May } & 0.003 & -0.02 & 0.007 & 0.05 & -0.007 & 0.01 \\
\hline & $(0.02)$ & $(0.04)$ & $(0.02)$ & $(0.06)$ & $(0.03)$ & $(0.02)$ \\
\hline \multirow[t]{2}{*}{ Public reaction May } & 0.001 & -0.006 & -0.01 & $0.1^{* *}$ & -0.0002 & -0.010 \\
\hline & $(0.03)$ & $(0.04)$ & $(0.02)$ & $(0.06)$ & $(0.03)$ & $(0.02)$ \\
\hline \multirow{2}{*}{ Govt reaction Dec } & -0.02 & -0.007 & -0.002 & 0.01 & -0.03 & 0.001 \\
\hline & $(0.02)$ & $(0.04)$ & $(0.02)$ & $(0.05)$ & $(0.03)$ & $(0.02)$ \\
\hline \multirow[t]{2}{*}{ Public reaction Dec } & -0.02 & 0.01 & -0.01 & 0.05 & -0.04 & 0.01 \\
\hline & $(0.02)$ & $(0.05)$ & $(0.02)$ & $(0.06)$ & $(0.03)$ & $(0.02)$ \\
\hline Demographic controls & Yes & Yes & Yes & Yes & Yes & Yes \\
\hline Pseudo $\mathrm{R}^{2}$ & 0.010 & 0.007 & 0.012 & 0.007 & 0.024 & 0.009 \\
\hline N observations & 981 & 977 & 986 & 1000 & 970 & 922 \\
\hline
\end{tabular}

Note: Second wave in December 2020. Demographic controls include log of household income per capita, employment status, urban/rural area, age, age squared, gender, and marital status. We report marginal effects for choosing the highest answer category from ordered probit estimations based on population weights. Standard errors are in parentheses. ${ }^{*} p<0.10,{ }^{* *} p<0.05,{ }^{* * *} p<0.01$ 


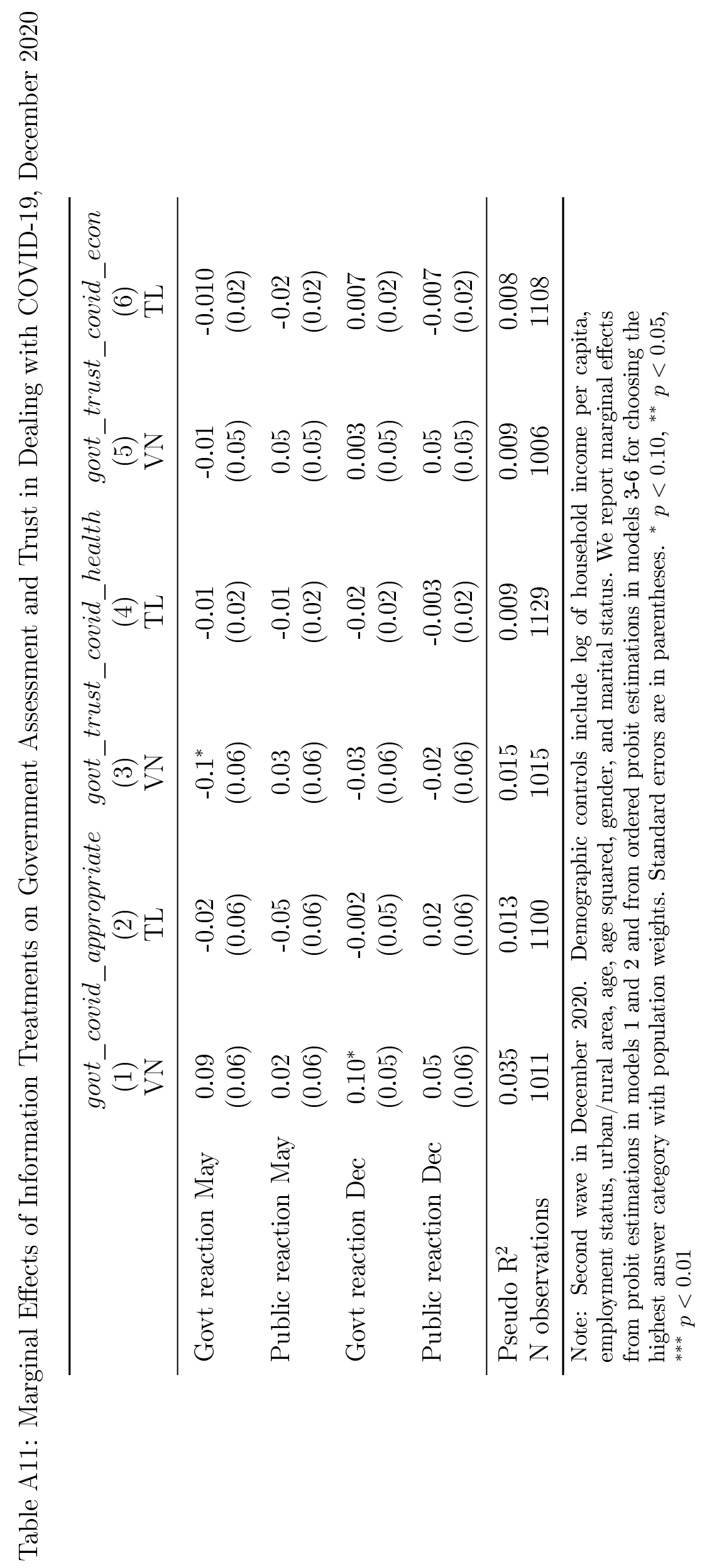


Table A12: Marginal Effects of Information Treatments on Concerns Due to COVID-19, December 2020

\begin{tabular}{lccccccccc}
\hline & \multicolumn{2}{c}{ concern_health } & \multicolumn{2}{c}{ concern_job } & \multicolumn{2}{c}{ concern_finance } & \multicolumn{2}{c}{ concern_econ } \\
& $(1)$ & $(2)$ & $(3)$ & $(4)$ & $(5)$ & $(6)$ & $(7)$ & $(8)$ \\
& VN & TL & VN & TL & VN & TL & VN & TL \\
\hline \multirow{2}{*}{ Govt reaction May } & -0.06 & $-0.1^{* *}$ & $-0.1^{*}$ & -0.08 & $-0.1^{* *}$ & -0.01 & -0.09 & $-0.1^{* *}$ \\
& $(0.06)$ & $(0.06)$ & $(0.05)$ & $(0.06)$ & $(0.06)$ & $(0.06)$ & $(0.06)$ & $(0.06)$ \\
Public reaction May & -0.05 & -0.06 & -0.03 & -0.08 & 0.002 & 0.03 & -0.03 & $-0.1^{* *}$ \\
& $(0.07)$ & $(0.06)$ & $(0.06)$ & $(0.06)$ & $(0.06)$ & $(0.06)$ & $(0.07)$ & $(0.06)$ \\
Govt reaction Dec & -0.05 & $-0.1^{* * *}$ & -0.06 & $-0.1^{*}$ & -0.08 & -0.03 & -0.09 & $-0.1^{* * *}$ \\
& $(0.07)$ & $(0.05)$ & $(0.06)$ & $(0.05)$ & $(0.07)$ & $(0.06)$ & $(0.06)$ & $(0.05)$ \\
Public reaction Dec & -0.05 & $-0.2^{* * *}$ & -0.01 & -0.08 & -0.06 & -0.005 & -0.07 & $-0.1^{* *}$ \\
& $(0.06)$ & $(0.06)$ & $(0.07)$ & $(0.06)$ & $(0.06)$ & $(0.06)$ & $(0.07)$ & $(0.06)$ \\
\hline Demographic controls & Yes & Yes & Yes & Yes & Yes & Yes & Yes & Yes \\
Pseudo R & 0.017 & 0.015 & 0.023 & 0.006 & 0.028 & 0.015 & 0.011 & 0.018 \\
N observations & 1006 & 1146 & 1004 & 1132 & 1004 & 1141 & 979 & 1136 \\
\hline
\end{tabular}

Note: Second wave in December 2020. Demographic controls include log of household income per capita, employment status, urban/rural area, age, age squared, gender, and marital status. We report marginal effects for choosing the highest answer category from ordered probit estimations with population weights. Standard errors are in parentheses. ${ }^{*} p<0.10,{ }^{* *} p<0.05,{ }^{* * *} p<0.01$ 


\section{A.3 Survey Questions}

Assessment of and trust in the government Before providing information treatments, we ask all respondents about their assessment of the government's macroeconomic policies before COVID-19, as follows:

- govt_ass_normal_times: As to the macroeconomic policy of the government before the COVID-19 outbreak -- we mean steps taken to fight inflation or unemployment-would you say the government was doing a good job, fair job, or a poor job? [Poor job, Fair job, Good job, Don't know]

After providing information treatments, we ask all respondents about their assessment of and trust in the government's policies in dealing with COVID-19, as follows:

- govt_covid_appropriate: Do you think the reaction of the government to the current COVID-19 outbreak is appropriate or not? [The reaction is not at all sufficient, The reaction is somewhat insufficient, The reaction is appropriate, The reaction is somewhat extreme, The reaction is much too extreme, I don't know]. govt_covid_appropriate is a dummy variable that takes value of unity if the answer is "appropriate" and zero otherwise.

- govt_trust_covid_health: How much do you trust the government to overcome the COVID-19 pandemic? [Strongly distrust, Somewhat distrust, Neither trust nor distrust, Somewhat trust, Strongly trust, I don't know]

- govt_trust_covid_econ: How much do you trust the government to mitigate the negative side-effects of social distancing on the economy, such as an increase in unemployment and a fall in production? [Strongly distrust, Somewhat distrust, Neither trust nor distrust, Somewhat trust, Strongly trust, I don't know]

\section{Macroeconomic expectations}

- $\pi^{e}$ : How do you think prices in general (which are used to measure the inflation rate) will develop over the next 12 months compared to the previous 12 months? They will [Decrease a lot, Decrease a little, Stay about the same, Increase a little, Increase a lot, I do not form opinions about future general price level, Don't know.]

- $u^{e}$ : How do you think unemployment will develop over the next 12 months compared to the previous 12 months? It will [Decrease a lot, Decrease a little, Stay about the same, Increase a little, Increase a lot, I do not form opinions about future unemployment, Don't know]

- $y^{e}$ : How do you think national economic growth (GDP growth) will develop over the next 12 months compared to the previous 12 months? It will [Decrease a lot, Decrease a little, Stay about the same, Increase a little, Increase a lot, I do not form opinions about future economic growth, Don't know] 


\section{Personal concerns}

- concern_health: How concerned are you about the effects that COVID-19 might have on your health or the health of other members of your household [Not at all concerned, Somewhat concerned, Very concerned, Don't know]

- concern_job: How concerned are you about the effects that COVID-19 might have on your job security or the job security of other members of your household [Not at all concerned, Somewhat concerned, Very concerned, Don't know]

- concern_finance: How concerned are you about the effects that COVID-19 might have on the financial situation of your household [Not at all concerned, Somewhat concerned, Very concerned, Don't know]

- concern_econ: How concerned are you about the effects that COVID-19 might have on the economy [Not at all concerned, Somewhat concerned, Very concerned, Don't know]

Consumer sentiment index Following the construction of the index of consumer sentiment by the University of Michigan (Surveys of Consumers), we calculate this index for each respondent as a simple average of the following five questions:

- Did the current financial situation of your household get better or worse over the past 12 months? [Got much worse, Got a bit worse, Stayed the same, Got a bit better, Got much better, Don't know]

- How do you think the financial situation of your household will develop over the next 12 months? [Get much worse, Get a bit worse, Stayed the same, Get a bit better, Get much better, Don't know]

- How do you think the national business conditions will develop over the next 12 months? [Get much worse, Get a bit worse, Stayed the same, Get a bit better, Get much better, Don't know]

- How do you think the national economic situation will develop over the next 5 years? [Get much worse, Get a bit worse, Stayed the same, Get a bit better, Get much better, Don't know]

- Generally speaking, do you think now is a good or bad time for people to buy major household items, such as furniture, a refrigerator, stove, television, and things like that? [Very bad, Bad, Neither good or bad, Good, Very good, Don't know] 